\title{
A comparison of atmospheric composition using the Carbon Bond and Regional Atmospheric Chemistry Mechanisms
}

\author{
G. Sarwar ${ }^{1}$, J. Godowitch ${ }^{1}$, B. H. Henderson ${ }^{2}$, K. Fahey ${ }^{1}$, G. Pouliot ${ }^{1}$, W. T. Hutzell ${ }^{1}$, R. Mathur ${ }^{1}$, D. Kang ${ }^{3}$, \\ W. S. Goliff ${ }^{4}$, and W. R. Stockwell ${ }^{5}$ \\ ${ }^{1}$ Atmospheric Modeling and Analysis Division, National Exposure Research Laboratory, US Environmental Protection \\ Agency, RTP, NC 27711, USA \\ ${ }^{2}$ Environmental Engineering Sciences, University of Florida, Gainesville, FL 32611, USA \\ ${ }^{3}$ Computer Sciences Corporation, RTP, NC 27709, USA \\ ${ }^{4}$ College of Engineering Center for Environmental Research and Technology, University of California at Riverside, Riverside, \\ CA 92507, USA \\ ${ }^{5}$ Department of Chemistry, Howard University, Washington, DC 20059, USA
}

Correspondence to: G. Sarwar (sarwar.golam@epa.gov)

Received: 22 February 2013 - Published in Atmos. Chem. Phys. Discuss.: 14 March 2013

Revised: 23 August 2013 - Accepted: 26 August 2013 - Published: 2 October 2013

\begin{abstract}
We incorporate the recently developed Regional Atmospheric Chemistry Mechanism (version 2, RACM2) into the Community Multiscale Air Quality modeling system for comparison with the existing 2005 Carbon Bond mechanism with updated toluene chemistry (CB05TU). Compared to CB05TU, RACM2 enhances the domain-wide monthly mean hydroxyl radical concentrations by $46 \%$ and nitric acid by $26 \%$. However, it reduces hydrogen peroxide by $2 \%$, peroxyacetic acid by $94 \%$, methyl hydrogen peroxide by $19 \%$, peroxyacetyl nitrate by $40 \%$, and organic nitrate by $41 \%$. RACM2 enhances ozone compared to CB05TU at all ambient levels. Although it exhibited greater overestimates at lower observed concentrations, it displayed an improved performance at higher observed concentrations. The RACM2 ozone predictions are also supported by increased ozone production efficiency that agrees better with observations. Compared to CB05TU, RACM2 enhances the domainwide monthly mean sulfate by $10 \%$, nitrate by $6 \%$, ammonium by $10 \%$, anthropogenic secondary organic aerosols by $42 \%$, biogenic secondary organic aerosols by $5 \%$, and in-cloud secondary organic aerosols by $7 \%$. Increased inorganic and organic aerosols with RACM2 agree better with observed data. Any air pollution control strategies developed using the two mechanisms do not differ appreciably.
\end{abstract}

\section{Introduction}

The composition of the atmosphere is understood through a combination of measurements and model predictions. Since measurements of composition are sparse in space, time, and chemical species; results of atmospheric chemical transport models fill in the gaps. Atmospheric chemical transport models are also used to develop air pollution control strategies to improve air quality for areas that do not meet ambient standards. Chemical transport models have many components, each of which has associated uncertainty. The model framework includes transport algorithms, deposition processes, meteorological fields, emissions, and atmospheric chemistry. The model's atmospheric chemistry is represented by a gasphase chemical mechanism. This study isolates the impact of atmospheric chemistry by implementing two different chemical mechanisms in a single chemical transport model.

Chemical mechanisms are continually updated to better represent laboratory studies and then tested in transport models. This summary will refer to three chemical mechanism series: State Air Pollution Research Center (SAPRC; e.g., Carter 1990, 2000, 2010), Carbon Bond (CB; e.g., Gery et al., 1989), and the Regional Atmospheric Chemistry Mechanism (RACM; e.g., Stockwell, 1997). The SAPRC mechanism is not used in this study, but like CB and RACM has had several generations (Carter, 1990, 2000, 2010). The CB mechanism 
was originally developed in the 1980s, and the fourth version (CB-IV) is widely used in urban to regional chemical transport models. Yarwood et al. (2005) updated CB-IV, now CB05, to accurately simulate pristine, wintertime, and high altitude conditions. Recently, Whitten et al. (2010) updated CB's toluene chemistry in CB05TU. The RACM mechanism (Stockwell et al., 1997) was derived from the Regional Acid Deposition Model (Stockwell, 1986; Stockwell et al., 1990) specifically to address regional application. Goliff et al. (2013) recently updated the RACM mechanism to version 2 (RACM2).

The development of mechanisms is typically based on smog-chamber studies, and subsequent studies evaluate the impact on chemical transport model predictions. In CMAQ, several studies have examined the impacts of CB-IV, CB05, SAPRC99, and SAPRC07 (Sarwar et al., 2008, 2011; Luecken, et al., 2008; Faraji et al., 2008; Cai et al., 2011; Hutzell, et al., 2012; Shearer et al., 2012). Only two regional modeling studies, with a European model, have focused on RACM2. Kim et al. (2009, 2011) compared an early version of RACM2 to CB05 over Europe and found increases in ozone (by $+5 \%)$ and most aerosols (sulfate $\left(\mathrm{SO}_{4}^{2-}\right)$ by $+16 \%$, nitrate $\left(\mathrm{NO}_{3}^{-}\right)$by $+11 \%$, ammonium $\left(\mathrm{NH}_{4}^{+}\right)$by $+10 \%$ ) except for secondary organic aerosols (SOA) (anthropogenic SOA by $-22 \%$, biogenic SOA by $-1 \%$ ). The impact of RACM2 on model predictions over the US is unknown since both previous RACM2 studies were conducted over Europe. The US contains a large range of meteorological and emission conditions controlling the formation of secondary pollutants, and therefore it provides a good region to examine the impacts of new chemical mechanisms. Here, we describe the impacts of CB05TU and RACM2 on model predictions using a chemical transport model.

\section{Methodology}

\subsection{Model framework}

The Community Multiscale Air Quality (CMAQ) modeling system is a three-dimensional chemical transport model and incorporates major atmospheric processes (Byun and Schere, 2006). Prior studies suggest that CMAQ can reasonably simulate atmospheric pollutants (e.g., Eder and $\mathrm{Yu}$, 2006; Appel et al., 2007; and Foley et al., 2010). We use the current CMAQ model (version 5) for this study (www. cmascenter.org). The horizontal domain covers the continental United States discretized using a $12 \mathrm{~km}$ grid resolution while the vertical extent consists of 35 layers and extends up to $50 \mathrm{hPa}$. Results from a global model (GEOS-CHEM, Bey et al., 2001) are used to derive boundary conditions for the study. The model used clean air vertical profiles as initial conditions and a 10 day spin-up period. The Weather Research and Forecasting (version 3.3) model (Skamarock et al., 2008) using an updated four-dimensional data assimi- lation approach (Gilliam et al., 2012) generated the meteorological fields for the study. The Meteorology-Chemistry Interface Processor was applied to develop the meteorological input data sets for the subsequent CMAQ simulations since these model runs were exercised in an offline mode. Gilliam and Pleim (2010) discussed performances for retrospective meteorological models. Meteorological fields used in the study are deemed adequate since the bias and error are better than those indicated by Gilliam and Pleim (2010).

\subsection{Gas-phase chemistry}

\subsubsection{CB05TU chemistry}

Details of the CB05TU chemistry have previously been described elsewhere (Yarwood et al., 2005; Whitten et al., 2010); only a brief summary is provided here. CB05TU uses a lumped structure approach for representing atmospheric chemistry. It consists of 172 chemical reactions including 20 photolytic reactions and uses 65 chemical species to describe atmospheric chemistry (Table 1). It uses kinetic data from the National Aeronautics and Space Administration/Jet Propulsion Laboratory (NASA/JPL) (Sander et al., 2003) and the International Union of Pure and Applied Chemistry (IUPAC) (Atkinson et al., 2005) review panels. The mechanism evaluation was completed by performing chamber simulations and comparing the simulation results with experimental data from the University of California, Riverside, and the University of North Carolina, Chapel Hill. It contains the bimolecular and ter-molecular hydrolysis of dinitrogen pentoxide $\left(\mathrm{N}_{2} \mathrm{O}_{5}\right)$. However, following the recent International Union of Pure and Applied Chemistry (IUPAC, 2010) recommendation, in the modified version used here, we (1) removed the ter-molecular hydrolysis of $\mathrm{N}_{2} \mathrm{O}_{5}$ and (2) lowered the rate constant for the bimolecular hydrolysis of $\mathrm{N}_{2} \mathrm{O}_{5}$. CB05TU also accounts for the production of sulfuric acid via the reaction of hydroxyl radical (HO) and sulfur dioxide $\left(\mathrm{SO}_{2}\right)$. However, we updated the rate constant of the reaction following the recent NASA/JPL recommendation, which is also consistent with the value used in RACM2.

\subsubsection{RACM2 chemistry}

The RACM2 mechanism described in Goliff et al. (2013) uses a lumped molecular approach for representing atmospheric chemistry. It consists of 363 chemical reactions including 33 photolytic reactions among 120 chemical species (Table 2). It uses kinetic data from several sources including the recent suggestions of IUPAC (IUPAC, 2010) and NASA/JPL (Sander et al., 2011). The mechanism evaluation was completed by performing chamber simulations and comparing the simulation results with experimental results from the EXACT campaign and the University of California, Riverside. It contains only the bimolecular hydrolysis of $\mathrm{N}_{2} \mathrm{O}_{5}$. Similar to CB05TU, we used the rate constant for the 
Table 1. Model chemical species in CB05TU* (Yarwood et al., 2005; Whitten et al., 2010).

\begin{tabular}{|c|c|c|c|}
\hline Species name & Description & Species name & Description \\
\hline NO & Nitric oxide & MEO2 & Methylperoxy radical \\
\hline $\mathrm{NO} 2$ & Nitrogen dioxide & $\mathrm{MEOH}$ & Methanol \\
\hline $\mathrm{O} 3$ & Ozone & MEPX & Methylhydroperoxide \\
\hline $\mathrm{O}$ & Oxygen atom (triplet) & FACD & Formic acid \\
\hline O1D & Oxygen atom (singlet) & ETHA & Ethane \\
\hline $\mathrm{OH}$ & Hydroxyl radical & $\mathrm{ROOH}$ & Higher organic peroxide \\
\hline $\mathrm{HO} 2$ & Hydroperoxy radical & AACD & Higher carboxylic acid \\
\hline $\mathrm{H} 2 \mathrm{O} 2$ & Hydrogen peroxide & PACD & Higher peroxycarboxylic acid \\
\hline NO3 & Nitrate radical & PAR & Paraffin carbon bond \\
\hline N2O5 & Dinitrogen pentoxide & ROR & Secondary alkoxy radical \\
\hline HONO & Nitrous acid & ETH & Ethene \\
\hline HNO3 & Nitric acid & OLE & Terminal olefin carbon bond \\
\hline PNA & Peroxynitric acid & IOLE & Internal olefin carbon bond \\
\hline $\mathrm{CO}$ & Carbon monoxide & ISOP & Isoprene \\
\hline FORM & Formaldehyde & ISPD & Isoprene product \\
\hline ALD2 & Acetaldehyde & TERP & Terpene \\
\hline $\mathrm{C} 2 \mathrm{O} 3$ & Acetylperoxy radical & TOL & Toluene and other monoalkyl aromatics \\
\hline PAN & Peroxyacetyl nitrate & XYL & Xylene and other polyalkyl aromatics \\
\hline ALDX & Higher aldehyde & CRES & Cresol and higher MW weight phenols \\
\hline CXO3 & Higher acylperoxy radical & TO2 & Toluene-hydroxyl radical adduct \\
\hline PANX & Higher peroxyacyl nitrate & OPEN & Aromatic ring opening product \\
\hline $\mathrm{XO} 2$ & $\mathrm{NO}$ to $\mathrm{NO} 2$ conversion (from $\mathrm{RNO} 2$ ) & CRO & Methylphenoxy radical \\
\hline $\mathrm{XO} 2 \mathrm{~N}$ & NO to RNO3 conversion (from $\mathrm{RO} 2$ ) & MGLY & Methylglyoxal and related products \\
\hline NTR & Organic nitrate (RNO3) & $\mathrm{SO} 2$ & Sulfur dioxide \\
\hline ETOH & Ethanol & SULF & Sulfuric acid (gaseous) \\
\hline CAT1 & Methyl-catechol & $\mathrm{HCO} 3$ & Adduct formed from FORM and $\mathrm{HO} 2$ \\
\hline CRON & Nitro-cresol & CRN2 & Peroxy radical from nitro-cresol \\
\hline CRNO & Alkoxy radical from nitro-cresol & CRPX & Nitro-cresol from hydroperoxide \\
\hline $\mathrm{CAO} 2$ & Peroxy radical from CAT1 & OPAN & PAN from OPO3 \\
\hline OPO3 & Peroxy radical from OPEN & & \\
\hline
\end{tabular}

* N2 (nitrogen), H2 (hydrogen), H2O (water vapor), M (air), O2 (oxygen), and CH4 (methane) are not listed. Prescribed constant concentrations are used in CMAQ for these species except $\mathrm{H} 2 \mathrm{O}$, which are used from meteorological files.

bimolecular hydrolysis of $\mathrm{N}_{2} \mathrm{O}_{5}$ following the recent IUPAC recommendation. It also accounts for the gas-phase production of sulfuric acid via the reaction of $\mathrm{HO}$ and $\mathrm{SO}_{2}$.

\subsection{Emissions}

The mapping of emissions of real organic species to emissions of mechanism species is a key component in the effective use of the condensed mechanism in air pollution models. The assignments for the CB05TU and RACM2 mechanisms were developed and can be obtained at http://www.engr. ucr.edu/ carter/emitdb. The 2005 National Emissions Inventory (http://www.epa.gov/ttn/chief/net/2005inventory.html\# inventorydata) was used as the starting point for generating model ready emissions. Emissions previously prepared for the AQMEII phase 1 project (Pouliot et al., 2012) were re-processed for CB05TU and RACM2. All other inputs needed for emission processing were unchanged for this study. The Sparse Matrix Operator Kernel Emissions (SMOKE) system (Houyoux et al., 2000) was used to gen- erate hourly, gridded, and speciated model ready emissions. All of the ancillary SMOKE inputs were based on the Version 4.2 2005 Modeling Platform (http://www.epa.gov/ttn/ chief/emch/index.html\#2005). Biogenic emissions were prepared using the Biogenic Emissions Inventory System (version 3.14) (Schwede et al., 2005).

\subsection{Aerosol chemistry}

The details of the CMAQ aerosol chemistry have been described in other studies (Binkowski and Roselle, 2003; Byun and Schere, 2006; Carlton et al., 2010). CMAQ describes the aerosol size distribution using three lognormal modes (Aitken, accumulation, and coarse). Aerosol species considered in CMAQ include inorganic aerosols, organic aerosols, sodium chloride, crustal materials, and other unspeciated material (Appel et al., 2013). Aqueous-phase oxidation of $\mathrm{S}(\mathrm{IV})$ by hydrogen peroxide $\left(\mathrm{H}_{2} \mathrm{O}_{2}\right), \mathrm{O}_{3}$, oxygen catalyzed by manganese $\left(\mathrm{Mn}^{2+}\right)$ and iron $\left(\mathrm{Fe}^{3+}\right)$, methylhydroperoxide (MEPX), and peroxyacetic acid (PACD) produce sulfate. 
Table 2. Model chemical species in RACM2* (Goliff et al., 2013).

\begin{tabular}{|c|c|c|c|}
\hline Species name & Description & Species name & Description \\
\hline $\mathrm{CO}$ & Carbon monoxide & ISOP & Peroxy radicals formed from ISO $+\mathrm{HO}$ \\
\hline NO & Nitric oxide & KET & Ketones \\
\hline $\mathrm{NO} 2$ & Nitrogen dioxide & KETP & Peroxy radicals formed from KET \\
\hline $\mathrm{O} 3$ & Ozone & LIM & d-limonene and other cyclic diene-terpenes \\
\hline $\mathrm{O} 3 \mathrm{P}$ & Ground state oxygen atom & LIMP & Peroxy radicals formed from LIM \\
\hline O1D & Excited state oxygen atom & MACP & Peroxy radicals formed from MACR $+\mathrm{HO}$ \\
\hline $\mathrm{HO}$ & Hydroxyl radical & MACR & Methacrolein \\
\hline $\mathrm{HO} 2$ & Hydroperoxy radical & MAHP & Hydroperoxides from MACP $+\mathrm{HO} 2$ \\
\hline $\mathrm{H} 2 \mathrm{O} 2$ & Hydrogen peroxide & MCP & $\begin{array}{l}\text { Methyl peroxy radical from MACR }+\mathrm{HO} \text { which does not } \\
\text { form MPAN }\end{array}$ \\
\hline NO3 & Nitrate radical & MCT & Methyl catechol \\
\hline $\mathrm{N} 2 \mathrm{O} 5$ & Dinitrogen pentoxide & МCTO & Alkoxy radical formed from $\mathrm{MCT}+\mathrm{HO}$ and $\mathrm{MCT}+\mathrm{NO} 3$ \\
\hline HONO & Nitrous acid & MCTP & Radical formed from $\mathrm{MCT}+\mathrm{O} 3$ reaction \\
\hline HNO3 & Nitric acid & MEK & Methyl ethyl ketone \\
\hline HNO4 & Peroxynitric acid & MEKP & Peroxy radicals formed from MEK \\
\hline $\mathrm{SO} 2$ & Sulfur dioxide & MGLY & Methylglyoxal and other alpha-carbonyl aldehydes \\
\hline SULF & Sulfuric acid & MO2 & Methyl peroxy radical \\
\hline ACD & Acetaldehyde & $\mathrm{MOH}$ & Methanol \\
\hline ACE & Acetylene & MPAN & $\begin{array}{l}\text { Peroxymethacryloylnitrate and other higher peroxyacylni- } \\
\text { trates from isoprene oxidation }\end{array}$ \\
\hline $\mathrm{ACO} 3$ & Acetyl peroxy radicals & MVK & Methyl vinyl ketone \\
\hline ACT & Acetone & MVKP & Peroxy radicals formed from MVK \\
\hline ACTP & Peroxy radicals formed from ACT & NALD & Nitrooxyacetaldehyde \\
\hline $\mathrm{ADCN}$ & Aromatic-NO3 adduct from PHEN & OLI & Internal alkenes \\
\hline ADDC & Aromatic-HO adduct from CSL & OLIP & Peroxy radicals formed from OLI \\
\hline ALD & C3 and higher aldehydes & OLND & NO3-alkene adduct reacting via decomposition \\
\hline API & $\begin{array}{l}\text { Alpha-pinenes and other cyclic } \\
\text { terpenes with one double bond }\end{array}$ & OLNN & NO3-alkene adduct reacting to form carbonitrates $+\mathrm{HO} 2$ \\
\hline APIP & Peroxy radicals formed from API & OLT & Terminal alkenes \\
\hline BALD & Benzaldehyde and other aromatic aldehydes & OLTP & Peroxy radicals formed from OLT \\
\hline BALP & Peroxy radicals formed from BALD & ONIT & Organic nitrate \\
\hline BAL1 & Peroxy radicals formed from BALD & OP1 & Methyl hydrogen peroxide \\
\hline BAL2 & Peroxy radicals formed from BALD & OP2 & Higher organic peroxides \\
\hline BEN & Benzene & ORA1 & Formic acid \\
\hline BENP & Peroxy radicals formed from BEN & ORA2 & Acetic acid and higher acids \\
\hline $\mathrm{CHO}$ & Phenoxy radical formed from CSL & ORAP & Peroxy radical formed from ORA $2+\mathrm{HO}$ reaction \\
\hline CSL & Cresol and other hydroxy substituted aromatics & PAA & Peroxyacetic acids and higher analogs \\
\hline DCB1 & Unsaturated dicarbonyls & PAN & Peroxyacetyl nitrate and higher saturated PANs \\
\hline DCB2 & Unsaturated dicarbonyls & PER1 & Peroxy intermediate formed from TOL \\
\hline DCB3 & Unsaturated dicarbonyls & PER2 & Peroxy intermediate formed from TOL \\
\hline DIEN & Butadiene and other anthropogenic dienes & PHEN & Phenol \\
\hline $\mathrm{EOH}$ & Ethanol & PHO & Phenoxy radical formed from phenol \\
\hline EPX & Epoxide formed in TOL, XYL and XYO reactions & PPN & Peroxypropionyl nitrate \\
\hline ETE & Ethene & $\mathrm{RCO} 3$ & Higher saturated acyl peroxy radicals \\
\hline ETEG & Ethylene glycol & $\mathrm{ROH}$ & C3 and higher alcohols \\
\hline ETEP & Peroxy radicals formed from ETE & TLP1 & Peroxy radicals formed from TOL \\
\hline ETH & Ethane & TOL & Toluene and less reactive aromatics \\
\hline ETHP & Peroxy radicals formed from ETH & TOLP & Peroxy radicals formed from TOL \\
\hline GLY & Glyoxal & TR2 & Peroxy radicals formed from TOL \\
\hline $\mathrm{HC} 3$ & $\begin{array}{l}\text { Alkanes, alcohols, esters and alkynes with } \mathrm{HO} \text { rate constant } \\
(298 \mathrm{~K}, 1 \mathrm{~atm}) \text { less than } 3.4 \times 10^{-12} \mathrm{~cm}^{3} \mathrm{~s}^{-1}\end{array}$ & UALD & Unsaturated aldehydes \\
\hline $\mathrm{HC} 3 \mathrm{P}$ & Peroxy radicals formed from $\mathrm{HC} 3$ & UALP & Peroxy radicals formed from UALD \\
\hline HC5 & $\begin{array}{l}\text { Alkanes, alcohols, esters and alkynes with } \mathrm{HO} \text { rate constant } \\
(298 \mathrm{~K}, 1 \mathrm{~atm}) \text { between } 3.4 \times 10^{-12} \\
\text { and } 6.8 \times 10^{-12} \mathrm{~cm}^{3} \mathrm{~s}^{-1}\end{array}$ & $\mathrm{XO} 2$ & Accounts for additional $\mathrm{NO}$ to $\mathrm{NO} 2$ conversions \\
\hline HC5P & Peroxy radicals formed from HC5 & $\mathrm{XY} 2$ & Peroxy radicals formed from XYL \\
\hline HC8 & $\begin{array}{l}\text { Alkanes, alcohols, esters and alkynes with } \mathrm{HO} \text { rate constant } \\
(298 \mathrm{~K}, 1 \mathrm{~atm}) \text { greater than } 6.8 \times 10^{-12} \mathrm{~cm}^{3} \mathrm{~s}^{-1}\end{array}$ & $\mathrm{XYO}$ & $o$-xylene \\
\hline HC8P & Peroxy radicals formed from $\mathrm{HC} 8$ & XYM & $m$-xylene \\
\hline $\mathrm{HCHO}$ & Formaldehyde & XYP & $p$-xylene \\
\hline HKET & Hydroxy ketone & XYL1 & Peroxy radicals formed from XYL \\
\hline ISHP & Beta-hydroxy hydroperoxides from ISOP $+\mathrm{HO} 2$ & XYLP & Peroxy radicals formed from XYL \\
\hline ISO & Isoprene & $\mathrm{XYO} 2$ & Peroxy radicals formed from XYO \\
\hline ISON & $\begin{array}{l}\text { Beta-hydroxyalkylnitrates from ISOP + NO } \\
\text { alkylnitrates from ISO + NO3 }\end{array}$ & XYOP & Peroxy radicals formed from $\mathrm{XYO}$ \\
\hline
\end{tabular}

\footnotetext{
* $\mathrm{N} 2, \mathrm{H} 2, \mathrm{H} 2 \mathrm{O}$ (water vapor), M (air), O2, and $\mathrm{CH} 4$ are not listed. Prescribed constant concentrations are used in CMAQ for these species except $\mathrm{H} 2 \mathrm{O}$, which are used from
} meteorological files. $\mathrm{CO} 2$ used in the original mechanism is not used in CMAQ. 
Sarwar et al. (2013) describe the details of the chemical reactions in aqueous phase. The model also accounts for the production of nitric acid $\left(\mathrm{HNO}_{3}\right)$ via the heterogeneous hydrolysis of $\mathrm{N}_{2} \mathrm{O}_{5}$. It currently uses the Davis et al. (2008) parameterization for the heterogeneous uptake coefficient that accounts for impacts of particle composition, water, phase of the particulate matter and temperature. CMAQv5.0 uses ISORROPIA II (Fountoukis and Nenes, 2007) to determine partitioning of inorganics between gas and aerosol phases.

The SOA in CMAQ is comprised of the contributions from anthropogenic sources, biogenic sources, and in-cloud processes. A detailed description of the SOA in CMAQ has been provided elsewhere (Carlton et al., 2010). Anthropogenic SOA is formed from the reactions of benzene, toluene, and xylene that produce organic peroxy radicals. These peroxy radicals react with nitric oxide (NO) to produce semi-volatile organic compounds or react with hydrogen peroxy radical $\left(\mathrm{HO}_{2}\right)$ to produce non-volatile SOA. Biogenic SOA is formed from the reactions of isoprene, monoterpene, and sesquiterpene that produce semi-volatile organic compounds. The model also accounts for acid enhanced pathway for isoprene SOA formation. Semi-volatile organics from anthropogenic and biogenic sources partition and form SOA. Semi-volatile organics also form non-volatile oligomers through particle phase-reactions. In-cloud SOA is formed from the aqueous-phase oxidation of glyoxal and methylglyoxal (Carlton et al., 2008, 2010). Glyoxal is not explicitly represented in CB05TU; therefore methylglyoxal with a Henry's Law coefficient adjusted to that of glyoxal is used to represent in-cloud SOA production when using CB05TU (Carlton et al., 2010). In contrast, RACM2 contains both glyoxal and methylglyoxal and are used explicitly in the model to produce in-cloud SOA.

\subsection{Simulation details}

Two simulations, one with each chemical mechanism, were completed for the month of September 2006. The US $\mathrm{O}_{3}$ season, a period marked by elevated regional $\mathrm{O}_{3}$ concentrations, runs from May through September. The 2006 Texas Air Quality Study (TexAQS) was conducted during AugustSeptember (Parrish et al., 2009) and thus the simulation period allows for a comparison of model predictions with observations from the 2006 TexAQS. The first simulation used CB05TU while the second simulation used RACM2. Differences in the results between the two simulations can thus be attributed to the differences in the chemical mechanisms. A third order numerical solver based on the Rosenbrock method (Sandu et al., 1997) was used to solve the system of ordinary differential equations representing gas-phase chemistry. The use of RACM2 increases computational time of the model by $37 \%$ compared to that of CB05TU. It should be noted that the increase is due to the combination of an increased number of chemical species in the chemistry as well as an increase in the number of transported species.

\section{Results and discussions}

\subsection{Impact on key oxidants}

\subsubsection{Impact on hydroxyl radical (HO)}

The importance of atmospheric HO is well established since it reacts with most atmospheric compounds and determines atmospheric oxidation capacity. The CB05TU predicted domain-wide monthly averaged $\mathrm{HO}$ is $0.05 \mathrm{pptv}$ while the RACM2 predicted value is $0.07 \mathrm{pptv}$; thus, RACM2 enhances overall $\mathrm{HO}$ by $46 \%$ (Table 3 ). Spatially resolved monthly mean $\mathrm{HO}$ obtained with CB05TU and the percent differences between RACM2 and CB05TU are shown in Fig. 1a and b. Spatially, the predicted mean HO with CB05TU ranged between 0.02 and 0.12 pptv with southern areas showing higher concentrations than northern areas. The southern plain states and portions of California, for example, have the highest predicted concentrations. RACM2 enhances HO by $12-36 \%$ in the eastern US and $36-60 \%$ in the western US due to several factors. First, it produces more $\mathrm{O}_{3}$ (described later) than CB05TU and thus generates more singlet oxygen atoms $\left(\mathrm{O}^{1} \mathrm{D}\right)$ via photolysis that subsequently enhances the production of $\mathrm{HO}$ via a reaction with water vapor $\left(\mathrm{H}_{2} \mathrm{O}\right)$. RACM2 also produces more $\mathrm{HO}$ than CB05TU from reactions of olefins and $\mathrm{O}_{3}$ due to higher production yields. RACM2 contains additional reaction products that can subsequently produce HO. For example, methyl acrolein is not an explicit chemical species in CB05TU, but in RACM2 it is separate and directly produces HO from photolysis. RACM2 uses a rate constant suggested by Mollner et al. (2010) for the $\mathrm{NO}_{2}+\mathrm{HO}$ reaction, which is lower than the value used in CB05TU. It reduces the loss of daytime $\mathrm{HO}$ and also enhances the concentration of HO in RACM2.

$\mathrm{HO}$ measurements are rare and insufficient to definitively conclude that our predictions are biased. The few available measurements of HO, however, support RACM2's enhancement of HO. Measurements of atmospheric HO concentrations in Houston during the $2006 \mathrm{TexAQS}$ have been reported by Mao et al. (2010a). Median predicted HO concentrations obtained with the two mechanisms are compared to the measurements in Houston in Fig. 1c. Both mechanisms capture the diurnal variation of the observed data; however, they both underpredict observed values both during the night and day. While CB05TU underpredicts the observed peak value by $30 \%$, RACM2 underpredicts observed HO by only $15 \%$. RACM2 captures the daytime observed values better than CB05TU. Although the underprediction discussed above is specific to Houston, these results are consistent with a growing body of literature showing model underprediction of $\mathrm{HO}$ radicals in a range of environments (Hofzumahaus et al., 2009; Whalley et al., 2011; Lu et al., 2013). 
Table 3. A summary of the comparison of CB05TU and RACM2 predicted domain-wide monthly mean values.

\begin{tabular}{|c|c|c|c|c|}
\hline Species & Unit & CB05TU & RACM2 & $\begin{array}{c}\text { Percent difference } \\
100 \times(\text { RACM } 2-\text { CB05TU }) / \text { CB05TU }\end{array}$ \\
\hline Hydroxyl radical (HO) & pptv & 0.05 & 0.07 & +46 \\
\hline Hydrogen peroxide $\left(\mathrm{H}_{2} \mathrm{O}_{2}\right)$ & pptv & 837 & 822 & -2 \\
\hline Peroxyacetic acid (PACD) & pptv & 400 & 26 & -94 \\
\hline Methylhydroperoxide (MEPX) & pptv & 492 & 398 & -19 \\
\hline Total nitrate $\left(\mathrm{TNO}_{3}\right)$ & pptv & 441 & 538 & +22 \\
\hline Nitric acid $\left(\mathrm{HNO}_{3}\right)$ & pptv & 289 & 364 & +26 \\
\hline Peroxyacetyl nitrate (PAN) & pptv & 232 & 141 & -40 \\
\hline Organic nitrate (NTR) & pptv & 378 & 222 & -41 \\
\hline Secondary nitrogen $\left(\mathrm{NO}_{\mathrm{Z}}\right)$ & pptv & 1305 & 1067 & -18 \\
\hline Oxides of nitrogen $\left(\mathrm{NO}_{\mathrm{X}}\right)$ & pptv & 1535 & 1570 & +2 \\
\hline Ozone $\left(\mathrm{O}_{3}\right)$ & ppbv & 36.6 & 38.8 & +6 \\
\hline Sulfate $\left(\mathrm{SO}_{4}^{2-}\right)$ & $\mu \mathrm{g} \mathrm{m}^{-3}$ & 1.47 & 1.61 & +10 \\
\hline Nitrate $\left(\mathrm{NO}_{3}^{-}\right)$ & $\mu \mathrm{g} \mathrm{m}^{-3}$ & 0.15 & 0.16 & +6 \\
\hline Ammonium $\left(\mathrm{NH}_{4}^{+}\right)$ & $\mu \mathrm{g} \mathrm{m}^{-3}$ & 0.37 & 0.41 & +10 \\
\hline Anthropogenic SOA & $\mu \mathrm{g} \mathrm{m}^{-3}$ & 0.07 & 0.10 & +42 \\
\hline Biogenic SOA & $\mu \mathrm{g} \mathrm{m}^{-3}$ & 0.40 & 0.42 & +5 \\
\hline In-cloud SOA & $\mu \mathrm{g} \mathrm{m}^{-3}$ & 0.01 & 0.011 & +11 \\
\hline Fine particles $\left(\mathrm{PM}_{2.5}\right)$ & $\mu \mathrm{g} \mathrm{m}^{-3}$ & 4.6 & 4.9 & +7 \\
\hline
\end{tabular}
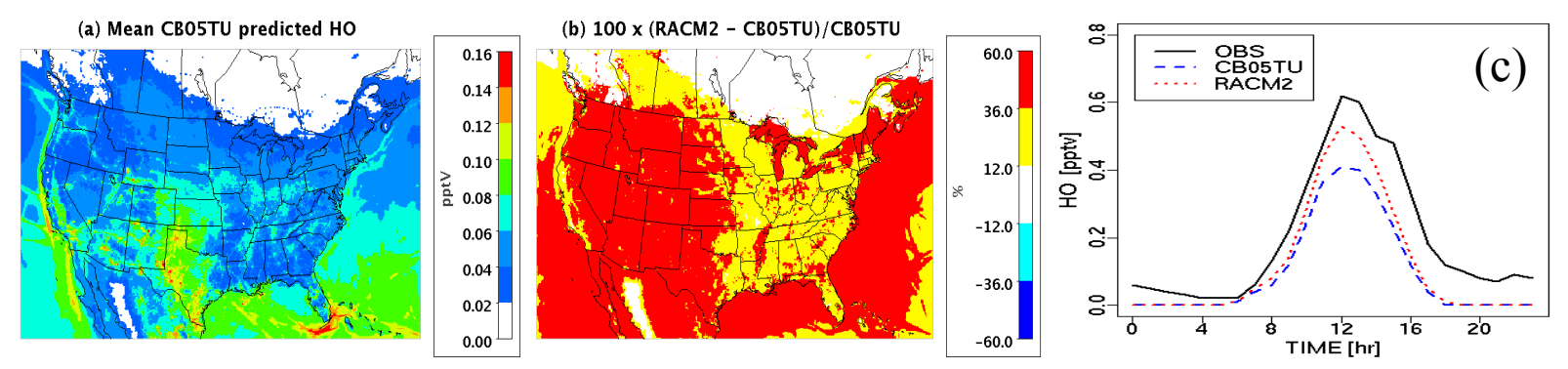

Fig. 1. (a) Predicted mean HO obtained with CB05TU, (b) percent differences in mean HO between RACM2 and CB05TU, (c) a comparison of predicted median HO to observed median data from the 2006 Texas Air Quality Study.

\subsubsection{Impact on hydrogen peroxide $\left(\mathrm{H}_{2} \mathrm{O}_{2}\right)$}

$\mathrm{H}_{2} \mathrm{O}_{2}$ is the most efficient aqueous-phase oxidant for the conversion of S(IV) into S(VI) (Seigneur and Saxena, 1988). Spatial predictions of monthly mean $\mathrm{H}_{2} \mathrm{O}_{2}$ obtained with CB05TU and the percent differences between the two mechanisms are shown in Fig. 2a and b. CB05TU predicts higher $\mathrm{H}_{2} \mathrm{O}_{2}$ values (>0.8 ppbv) over the southern and western areas of the modeling domain. It predicts lower $\mathrm{H}_{2} \mathrm{O}_{2}$ values $(<0.6 \mathrm{ppbv})$ over Canada, the Midwest and northeastern US. RACM2 decreases $\mathrm{H}_{2} \mathrm{O}_{2}$ by $9-15 \%$ in most areas except in the southwestern US where it decreases $\mathrm{H}_{2} \mathrm{O}_{2}$ by $3-9 \%$. In both mechanisms, $\mathrm{H}_{2} \mathrm{O}_{2}$ is produced from the reactions of $\mathrm{HO}_{2}+\mathrm{HO}_{2}=\mathrm{H}_{2} \mathrm{O}_{2}+\mathrm{O}_{2}$ and $\mathrm{HO}_{2}+\mathrm{HO}_{2}+\mathrm{H}_{2} \mathrm{O}=\mathrm{H}_{2} \mathrm{O}_{2}+\mathrm{O}_{2}+\mathrm{H}_{2} \mathrm{O}$, while it is consumed by photolysis and the reaction with $\mathrm{HO}$. The rate constant for the reaction of $\mathrm{H}_{2} \mathrm{O}_{2}$ and $\mathrm{HO}$, and the photolysis frequencies are similar in both mechanisms. Unlike CB05TU,
RACM2 produces $\mathrm{H}_{2} \mathrm{O}_{2}$ from alkene/ $\mathrm{O}_{3}$ reactions. However, their contributions are generally small and do not affect the overall production of $\mathrm{H}_{2} \mathrm{O}_{2}$. The rate constants for the reactions producing $\mathrm{H}_{2} \mathrm{O}_{2}$ are similar in both mechanisms. However, RACM2 produces lower $\mathrm{H}_{2} \mathrm{O}_{2}$ because it also predicts lower $\mathrm{HO}_{2}$ except over salt-water bodies. Consistent with the enhanced $\mathrm{HO}_{2}$ predictions over salt-water bodies, RACM2 increases $\mathrm{H}_{2} \mathrm{O}_{2}$ by $3-15 \%$ over salt-water bodies.

\subsubsection{Impact on peroxyacetic acid (PACD)}

PACD is an aqueous-phase oxidant that plays an important role in the conversion of $\mathrm{S}(\mathrm{IV})$ into $\mathrm{S}(\mathrm{VI})$. The spatial pattern of predicted PACD with CB05TU is similar to that of $\mathrm{H}_{2} \mathrm{O}_{2}$ (Fig. 2c). CB05TU predicts higher values ( $>0.4 \mathrm{ppbv})$ over the southern and western areas of the modeling domain. It predicts lower values ( $<0.3 \mathrm{ppbv})$ over Canada, the Midwest and northeastern US. RACM2 reduces PACD in most areas by $60-100 \%$ (Fig. 2 d). PACD is formed from the reactions 
(a) CB05TU predicted $\mathrm{H} 2 \mathrm{O} 2$

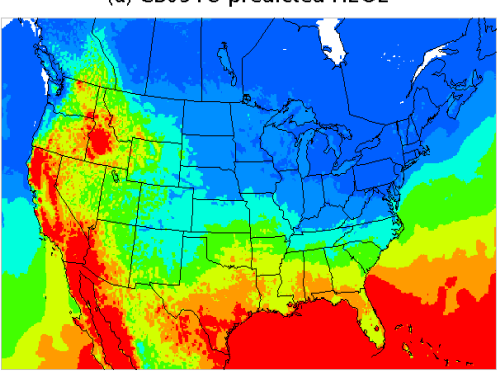

(c) CB05TU predicted PACD

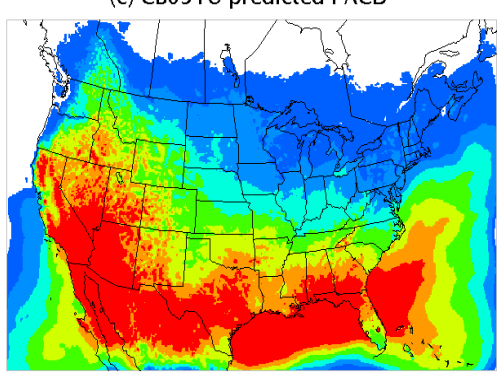

(e) CB05TU predicted MEPX

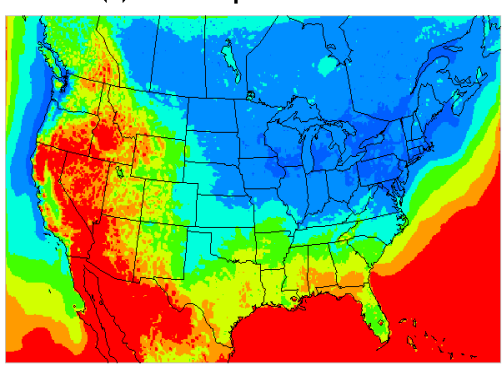

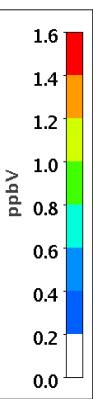
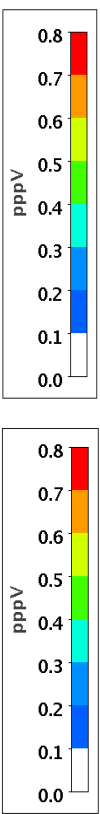

(b) $100 \times($ RACM2 - CB05TU)/CB05TU

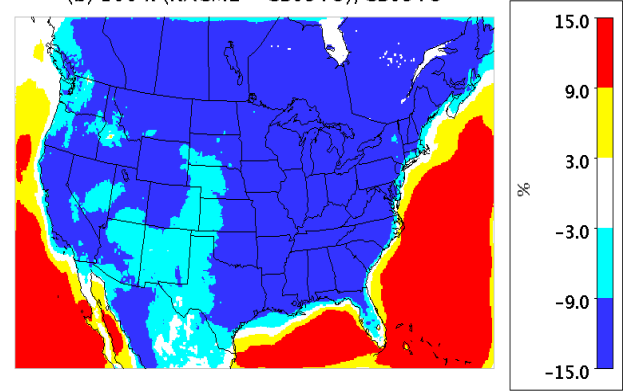

(d) $100 \times$ (RACM2 - CB05TU)/CB05TU

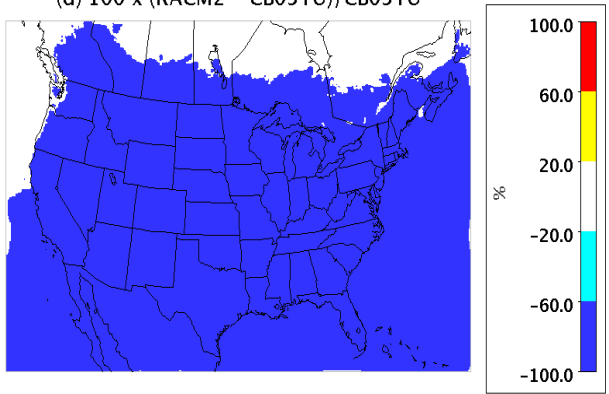

(f) $100 \times($ RACM2 - CB05TU)/CB05TU

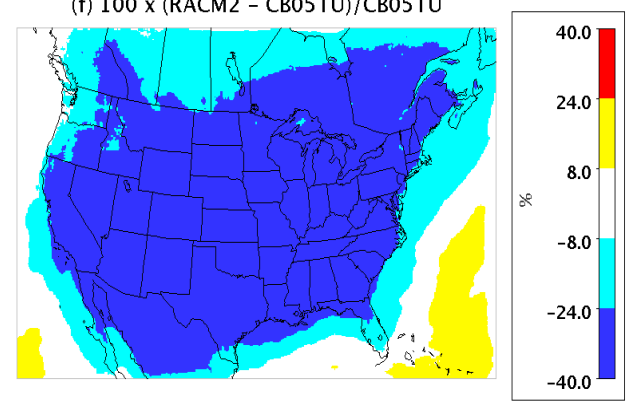

Fig. 2. (a) Predicted mean $\mathrm{H}_{2} \mathrm{O}_{2}$ obtained with $\mathrm{CB} 05 \mathrm{TU}$, (b) percent differences in mean $\mathrm{H}_{2} \mathrm{O}_{2}$ between RACM2 and CB05TU, (c) predicted mean PACD with CB05TU, (d) percent differences in mean PACD between RACM2 and CB05TU, (e) predicted mean MEPX obtained with CB05TU (f) percent differences in mean MEPX between RACM2 and CB05TU.

of acetyl peroxy and higher acyl peroxy radicals with $\mathrm{HO}_{2}$. In RACM2, yields of PACD productions from these reactions are only $50 \%$ of those in CB05TU and predictions of $\mathrm{HO}_{2}$, acetyl peroxy radical, higher peroxy radical are also lower than those obtained with CB05TU. Additionally, RACM2 photolysis frequencies of PACD are about two times greater and the rate constant for the reaction of PACD with $\mathrm{HO}$ is also greater ( 7 times greater at $298 \mathrm{~K}$ and $1.0 \mathrm{~atm}$ ) than those in CB05TU. Thus, RACM2 predicts much lower PACD concentrations compared to those with CB05TU.

Measurements of PACD for the simulation period are not readily available for comparison with model predictions. Zhang et al. (2010) measured PACD in an urban (Beijing) and two rural areas (Backgarden and Mazhuang) in China. Measurements were conducted at three different periods (2006, 2007, and 2008) in Beijing and one time period in Backgarden (2006) and Mazhuang (2008). We calculated mean values for the entire sampling period from reported daytime and nighttime mean values. The mean value for Bei- jing is 34 pptv in 2006, 113 pptv in 2007, and 36 pptv in 2008. The mean value for Backgarden is $27 \mathrm{pptv}$ and for Mazhuang it is 117 pptv. CB05TU predicted monthly mean in southern and western areas of the modeling domain range between 500 and $1000 \mathrm{pptv}$ while predictions for the northern area range between 50 and 300 pptv. RACM 2 predicted monthly mean in the southern and western areas range between 30 and $60 \mathrm{pptv}$ while predictions for the northern area generally range between 10 and $30 \mathrm{pptv}$. We also analyzed CB05TU predictions for a summer month (July) in 2006. Predicted values are even greater than the predictions in September. Many studies have reported that current air pollution levels in China are much greater than in the US. Thus, PACD levels in China are likely to be greater than those in the US. In the absence of any measurements in the US, we compare our predictions to the higher observed values in China and find that $\mathrm{CB} 05 \mathrm{TU}$ predictions are an order of magnitude greater than the higher observed values in China. While the CB05TU predictions are too high, the RACM2 predictions appear to be 

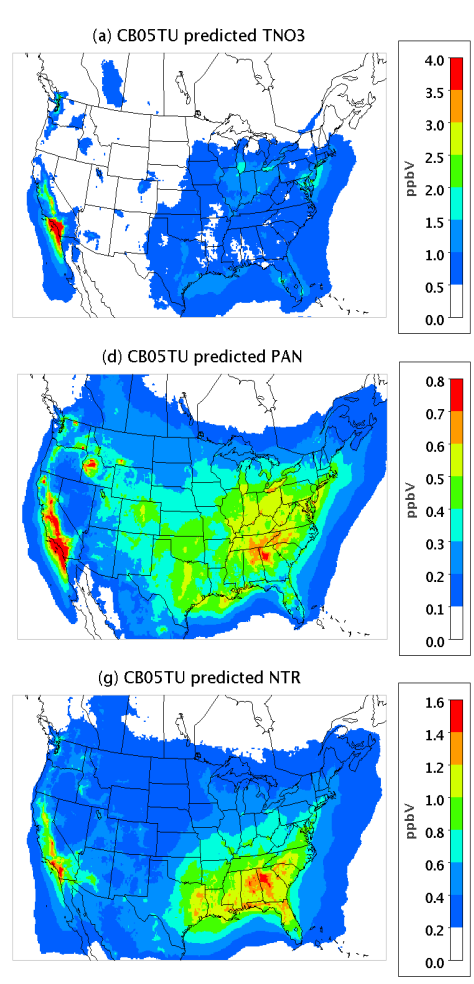
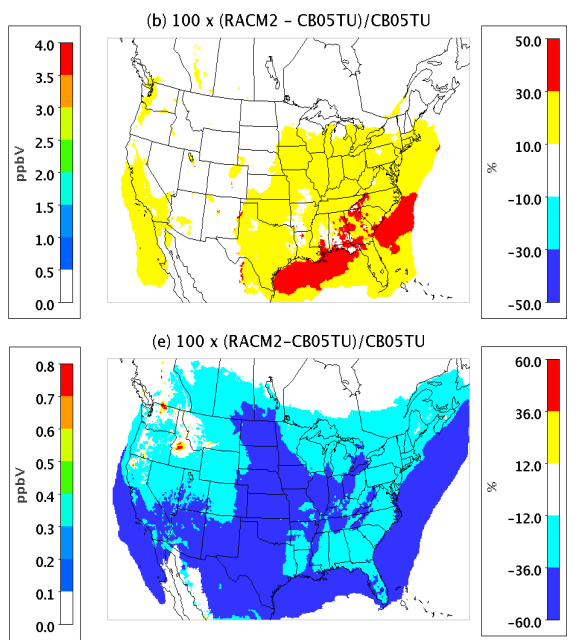

(h) $100 \times$ (RACM2-CB05TU)/CB05TU

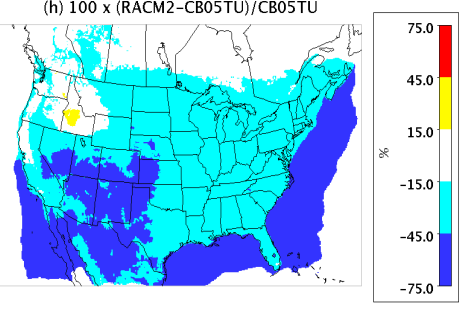

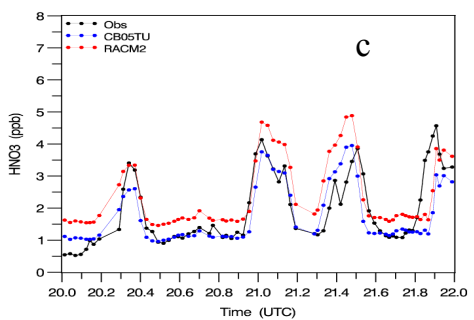

Time (UTC)

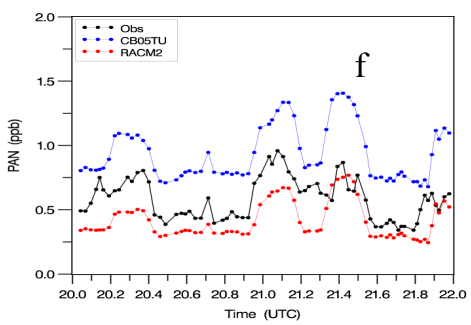

Time (UTC)

Fig. 3. (a) Predicted mean $\mathrm{TNO}_{3}$ obtained with CB05TU, (b) percent differences in mean $\mathrm{TNO}_{3}$ between $\mathrm{RACM} 2$ and $\mathrm{CB} 05 \mathrm{TU}$, (c) a comparison of predicted $\mathrm{HNO}_{3}$ to aircraft-based measurements from the 2006 Texas Air Quality Study (13 September), (d) predicted mean PAN obtained with CB05TU, (e) percent differences in mean PAN between RACM2 and CB05TU, (f) a comparison of predicted PAN to aircraft-based measurements from the 2006 Texas Air Quality Study (13 September), (g) predicted mean NTR obtained with CB05TU, (h) percent differences in mean NTR between RACM2 and CB05TU.

similar in magnitude for such a comparison. Measurements of atmospheric PACD levels in the US are needed for a more robust comparison with the model predictions.

\subsubsection{Impact on methylhydroperoxide (MEPX)}

MEPX is also an oxidant for the aqueous-phase oxidation of $\mathrm{S}(\mathrm{IV})$ to $\mathrm{S}(\mathrm{VI})$. Similar to $\mathrm{H}_{2} \mathrm{O}_{2}$ and PACD, CB05TU predicts the higher MEPX levels (>0.4 ppbv) over the southern and western areas of the modeling domain (Fig. 2e) and lower values ( $<0.3 \mathrm{ppbv})$ in Canada, the Midwest, and northeastern US. RACM2 reduces MEPX over most land areas of the modeling domain by $24-40 \%$ while increasing predicted values by $8-24 \%$ over some water bodies (Fig. 2f). MEPX is formed from the reaction of methyl peroxy radical and $\mathrm{HO}_{2}$, while it is consumed by photolysis and the reaction with HO. The rate constant for the reaction of MEPX and HO in RACM2 is lower (almost $30 \%$ lower at $298 \mathrm{~K}$ and $1.0 \mathrm{~atm})$ than that in CB05TU. RACM2 photolysis frequencies of MEPX are approximately $10 \%$ greater than those in CB05TU, which consumes more MEPX. The rate constant for the formation reaction is similar in both mechanisms. RACM2 predicts lower $\mathrm{HO}_{2}$, thus the production rate of MEPX is also lower.

\subsection{Impact on nitrogen species}

\subsubsection{Impact on total nitrate $\left(\mathrm{TNO}_{3}\right)$}

Predicted monthly mean $\mathrm{TNO}_{3}$ with CB05TU and the percent differences between the two mechanisms are shown in Fig. 3a and b. Here, $\mathrm{TNO}_{3}$ represents the sum of $\mathrm{HNO}_{3}$, fineparticulate nitrate, and coarse-particulate nitrate. CB05TU predicts the highest $\mathrm{TNO}_{3}$ in southern California and the lowest $\mathrm{TNO}_{3}$ in large areas of the western US and Canada (Fig. 3a). CB05TU predicts concentrations of $0.5-1.5 \mathrm{ppbv}$ over most of the eastern US. RACM2 increases $\mathrm{TNO}_{3}$ by $30-50 \%$ in some areas of southeastern US, coastal areas of the Gulf of Mexico, and some areas of the eastern seaboard, and $10-30 \%$ in most of the eastern US and California. The important $\mathrm{HNO}_{3}$ production pathways are the daytime production via the reaction of $\mathrm{NO}_{2}$ and $\mathrm{HO}$ and the nighttime production via the homogeneous and heterogeneous hydrolysis of $\mathrm{N}_{2} \mathrm{O}_{5}$. The RACM2 rate constant for the reaction of $\mathrm{NO}_{2}$ and $\mathrm{HO}$ is slightly lower than that of the CB05TU value. However, RACM2 predicted $\mathrm{HO}$ concentrations are greater than those obtained with CB05TU; consequently, the daytime production of $\mathrm{HNO}_{3}$ by RACM2 is greater than that by CB05TU. In addition, a fraction of the reaction of NO and 
$\mathrm{HO}_{2}$ in RACM2 produces $\mathrm{HNO}_{3}$, which also contributes to the additional daytime $\mathrm{HNO}_{3}$ production compared to that obtained with CB05TU. Changes in the nighttime production of $\mathrm{HNO}_{3}$ between the two mechanisms are much smaller than that of the daytime production.

Predicted $\mathrm{HNO}_{3}$ results are compared to measurements from the NOAA-WP3 research aircraft during the 2006 TexAQS (13 September) in Fig. 3c. Both mechanisms track the variation of observed concentrations outside and within the Dallas-Fort Worth urban plumes along the flight path. While CB05TU predictions generally follow the observed data, RACM2 predictions tend to slightly overpredict compared to the observed data. However, CB05TU underpredicts the first and the last observed peaks when RACM2 captures the observed data better. The overall slope of the fitted line of model predictions versus observations from multiple flights was 0.87 for CB05TU and 1.13 for RACM2. Similar results are obtained for comparisons with aircraft measurements on other days as well as surface measurements from the Clean Air Status and Trends Network (CASTNET). We also compared CB05TU predictions from other model simulations to CASTNET measurements (not shown here) and found that it underpredicts $\mathrm{HNO}_{3}$ compared to the observed data in summer months. Though RACM2 tended to overpredict $\mathrm{HNO}_{3}$ in September, it may improve the model underpredictions in summer months.

\subsubsection{Impact on peroxyacetyl nitrate (PAN)}

Predicted monthly mean PAN with CB05TU and the percent differences between the two mechanisms are shown in Fig. 3d and e. CB05TU predicted monthly mean PAN concentrations are greater than $0.1 \mathrm{ppbv}$ across the US. Concentrations greater than $0.4 \mathrm{ppbv}$ are predicted in the Mid Atlantic States, the Midwest, southern plains, California, and Idaho. The highest PAN is predicted in California while the lowest values are predicted in northern Canada. RACM2 decreases PAN by $36-60 \%$ in plain states, the Midwest and California and $12-36 \%$ in other areas. PAN is formed from the reaction of acetyl peroxy and nitrogen dioxide $\left(\mathrm{NO}_{2}\right)$. The primary reasons for the decrease in PAN with RACM2 are (1) a lower rate constant $(15 \%$ lower at $298 \mathrm{~K}$ and $1.0 \mathrm{~atm})$ for the PAN formation reaction, (2) a higher rate constant for the thermal decomposition reaction of PAN, and (3) RACM2 contains two photolysis channels one of which produces acetyl peroxy, which can produce more PAN, while the other does not. CB05TU contains only one photolysis channel, which produces acetyl peroxy that can recombine with $\mathrm{NO}_{2}$ to reproduce PAN. RACM2 predicted acetyl peroxy radical is lower than that obtained with CB05TU, which also contributes to the lower production of PAN. In addition, RACM2 also contains a reaction involving PAN and $\mathrm{HO}$, which consumes additional PAN though its impact is small. The increases in PAN with RACM2 in Idaho are pri- marily due to differences in speciation of biomass emissions and subsequent reactions.

Predicted PAN concentrations are compared to the aircraft measurements along the same flight path in Fig. 3f. Both mechanisms track the variation of observed PAN concentrations outside and within the Dallas-Fort Worth urban plumes along the flight path. However, CB05TU considerably overpredicts PAN compared to observed data, while RACM2 slightly underpredicts the observed data. Overall, CB05TU overpredicts PAN by $50 \%$ compared to observed data, while RACM2 predictions are lower than observed values by $10 \%$. Predictions on other days also show similar agreement with observed data. Previous studies (Yu et al., 2010, 2012) comparing model predictions obtained with CBIV and CB05 mechanisms to observed PAN from several field campaigns have also noted that these mechanisms overpredict PAN. Thus, the chemistry in RACM2 has improved the predictions of PAN. Although not shown here, RACM2 also reduces the predictions of peroxypropionyl nitrate compared to those obtained with CB05TU by similar magnitudes.

\subsubsection{Impact on organic nitrate (NTR)}

CB05TU contains only one organic nitrate species (NTR) while RACM2 contains several organic nitrate species. All organic nitrate species in RACM2 are added for comparison with NTR of CB05TU. Predicted monthly mean NTR with CB05TU and the percent differences between the two mechanisms are shown in Fig. 3g and h. Predicted NTR concentrations with CB05TU are greater than $0.2 \mathrm{ppbv}$ across the entire US. Values greater than $0.8 \mathrm{ppbv}$ are predicted in the southeastern US and California. RACM2 decreases NTR by $45-75 \%$ in the southwestern US and Mexico and 15$45 \%$ in other areas due to several factors including: (1) NTR yields for many reactions in RACM2 are lower than those in CB05TU, and (2) the rate constant for the NTR + HO in RACM2 is 13 times greater than that in CB05TU and so consumes more NTR. As mentioned earlier, RACM2 produces greater HO than CB05TU; thus, the consumption of NTR via $\mathrm{HO}$ in RACM2 is substantially greater than in CB05TU. RACM2 increases NTR in Idaho primarily due to differences in speciation of biomass emissions and subsequent reactions. Measurements of organic nitrates are not readily available for the simulation period for comparison with model predictions.

\subsubsection{Impact on secondary nitrogen species $\left(\mathrm{NO}_{\mathrm{z}}\right)$}

Predicted monthly mean $\mathrm{NO}_{z}$ with $\mathrm{CB} 05 \mathrm{TU}$ and the percent differences between the two mechanisms are shown in Fig. $4 \mathrm{a}$ and $\mathrm{b}$. Here, we define $\mathrm{NO}_{\mathrm{z}}$ as the sum of all products of $\mathrm{NO}_{\mathrm{x}}$ oxidation (i.e., secondary nitrogen species including gaseous and particulate nitrogen species; Trainer et al., 2000). Thus, $\mathrm{NO}_{\mathrm{Z}}$ for $\mathrm{CB} 05 \mathrm{TU}$ is defined as $\mathrm{NO}_{\mathrm{Z}}=\mathrm{NO}_{3}$ $+2 \times \mathrm{N}_{2} \mathrm{O}_{5}+\mathrm{HONO}+\mathrm{HNO}_{3}+\mathrm{PAN}+\mathrm{PANX}+\mathrm{PNA}+$ $\mathrm{NTR}+\mathrm{CRON}+\mathrm{CRNO}+\mathrm{CRN} 2+\mathrm{CRPX}+\mathrm{OPAN}+\mathrm{ANO}_{3}$; 

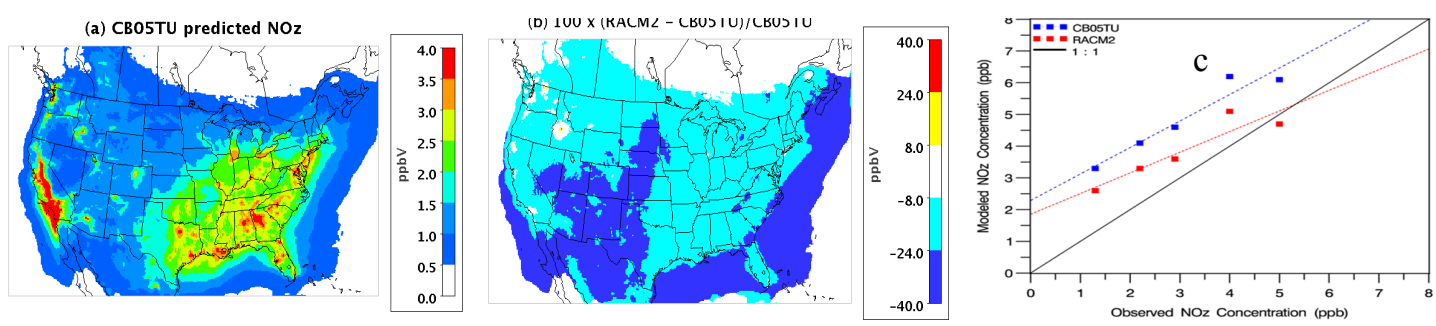

Fig. 4. (a) Predicted mean $\mathrm{NO}_{\mathrm{Z}}$ obtained with CB05TU, (b) percent differences in mean $\mathrm{NO}_{\mathrm{z}}$ between RACM2 and CB05TU, (c) a comparison of predicted $\mathrm{NO}_{\mathrm{Z}}$ to measurements from the Yorkville site of the South Eastern Aerosol Research and Characterization.
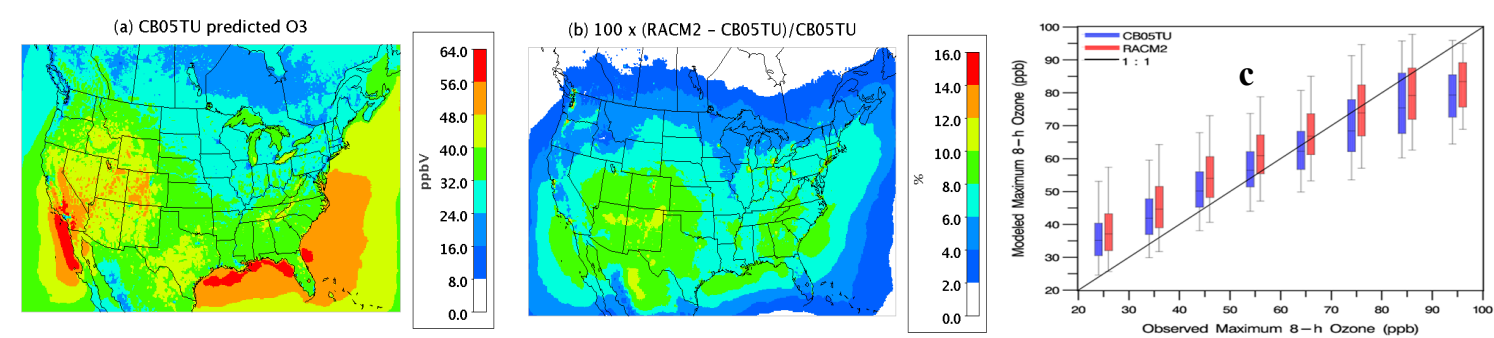

Fig. 5. (a) Predicted mean surface $\mathrm{O}_{3}$ obtained with CB05TU, (b) percent differences in mean $\mathrm{O}_{3}$ between RACM2 and CB05TU, (c) a comparison of predicted mean $8 \mathrm{~h} \mathrm{O}_{3}$ to observations from the Air Quality System.

where all gaseous chemical species are defined in Table 1 and $\mathrm{ANO}_{3}$ is aerosol particulate nitrate. Similarly, $\mathrm{NO}_{\mathrm{z}}$ for RACM2 is defined as $\mathrm{NO}_{z}=\mathrm{NO}_{3}+2 \times \mathrm{N}_{2} \mathrm{O}_{5}+\mathrm{HONO}+$ $\mathrm{HNO}_{3}+\mathrm{PAN}+\mathrm{PPN}+\mathrm{MPAN}+\mathrm{HNO}_{4}+\mathrm{ISON}+\mathrm{ONIT}$ $+\mathrm{NALD}+\mathrm{ADCN}+\mathrm{OLNN}+\mathrm{OLND}+\mathrm{ANO}_{3}$; where all gaseous chemical species are defined in Table 2. CB05TU predicted $\mathrm{NO}_{\mathrm{z}}$ concentrations are greater than $0.5 \mathrm{ppbv}$ for all areas in the US. Values greater than $3.5 \mathrm{ppbv}$ are predicted in southern California while 2.0-4.0 ppbv are predicted in the vicinity of major urban areas of the eastern US. RACM2 decreases $\mathrm{NO}_{\mathrm{z}}$ by $24-40 \%$ in areas of the southwestern US, the Gulf of Mexico, and the Atlantic Ocean, and by 8-24\% in other areas. As discussed earlier, RACM2 enhances $\mathrm{TNO}_{3}$ while decreasing predictions of PAN, PPN, and NTR compared to CB05TU. The decreases in PAN, PPN, and NTR overwhelm the increases in $\mathrm{TNO}_{3}$; consequently, RACM2 decreases $\mathrm{NO}_{\mathrm{z}}$.

The major components of $\mathrm{NO}_{\mathrm{Z}}$ are $\mathrm{TNO}_{3}$, PAN and NTR, which account for $81 \%$ in CB05TU (mean domain-wide value) and $84 \%$ in $\mathrm{RACM} 2 . \mathrm{TNO}_{3}$ is the most dominant chemical species in mean $\mathrm{NO}_{z}$ accounting for $34 \%$ of $\mathrm{NO}_{\mathrm{z}}$ in CB05TU. NTR is the second most dominant chemical species and accounts for $29 \%$ of $\mathrm{NO}_{\mathrm{Z}}$ in CB05TU. RACM2 lowers NTR by $41 \%$ compared to that of CB05TU and is the primary reason for the reduction in $\mathrm{NO}_{\mathrm{z}}$. PAN accounts for $18 \%$ of the mean $\mathrm{NO}_{\mathrm{z}}$ in CB05TU. RACM2 lowers PAN by $40 \%$ compared to CB05TU, which also contributes to the reduction in $\mathrm{NO}_{\mathrm{z}}$.

Both $\mathrm{NO}_{\mathrm{y}}$ and $\mathrm{NO}_{\mathrm{x}}$ concentrations are measured in the Southeastern Aerosol Research and Characterization (SEARCH) network. $\mathrm{NO}_{\mathrm{z}}$ concentrations are derived by sub- tracting $\mathrm{NO}_{\mathrm{x}}$ from $\mathrm{NO}_{\mathrm{y}}$ measurements and are compared to the predicted $\mathrm{NO}_{\mathrm{z}}$ values for the Yorkville site in Fig. 4c. CB05TU overpredicts $\mathrm{NO}_{z}$ compared to the observed data while RACM2 predictions agree better with the observed data.

\subsection{Impact on $\mathrm{O}_{3}$}

\subsubsection{Impact on surface $\mathrm{O}_{3}$}

Predicted monthly mean $\mathrm{O}_{3}$ with CB05TU and the percent differences between the two mechanisms are shown in Fig. 5a and b. Mean predicted $\mathrm{O}_{3}$ concentrations are greater than $24 \mathrm{ppbv}$ in all areas of the US. Predicted $\mathrm{O}_{3}$ concentrations are the highest in southern California and the lowest in northern Canada. Predicted mean $\mathrm{O}_{3}$ is lower in the eastern US than in the western US. Mean values are greater in the southern US and Mexico than those in the northern US and Canada. RACM2 increases $\mathrm{O}_{3}$ in most of the modeling domain (Fig. 5b). The increases are greater (generally 6-12\%) in the southern area of the domain while smaller $(0-6 \%)$ increases are predicted in the northern area of the domain. Kim et al. (2009) also compared $\mathrm{O}_{3}$ predictions from the two mechanisms over Europe and noted that RACM2 predicted higher $\mathrm{O}_{3}$ than $\mathrm{CB} 05$. Several factors in RACM2 increase $\mathrm{O}_{3}$ compared to CB05TU: (1) while the $\mathrm{NO}_{2}$ photolysis frequencies in RACM2 are higher, the rate constant for the titration of $\mathrm{O}_{3}$ by NO in RACM2 is lower; (2) a lower rate constant for the $\mathrm{NO}_{2}+\mathrm{HO}$ reaction; (3) $\mathrm{NO}_{\mathrm{x}}$ recycling from organic nitrate and other species is greater in RACM2; and (4) some of the organic chemistry (especially aromatic 


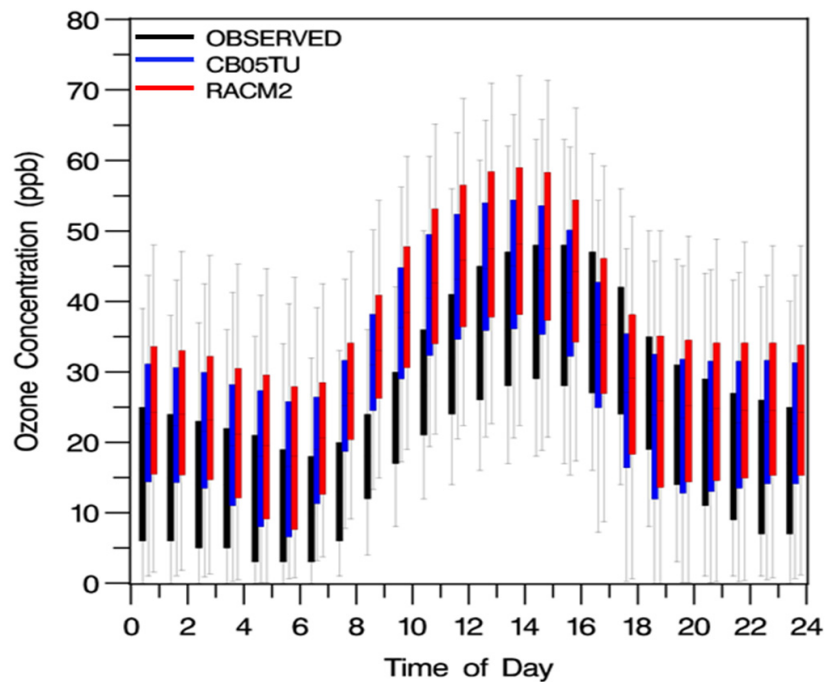

Fig. 6. A comparison of diurnal variation of predicted hourly surface $\mathrm{O}_{3}$ obtained with CB05TU, RACM2 and observations from Air Quality System sites.

chemistry) produces more $\mathrm{RO}_{2}$ in $\mathrm{RACM} 2$; thus, the conversion of $\mathrm{NO}$ into $\mathrm{NO}_{2}$ via the $\mathrm{NO}$ and $\mathrm{RO}_{2}$ reaction is greater in RACM2. Kim et al. (2009) provide a more detailed description of the differences in the two mechanisms that lead to enhanced $\mathrm{O}_{3}$ formation in RACM2.

Daily maximum $8 \mathrm{~h} \mathrm{O}_{3}$ concentrations are calculated using ambient monitoring data from the AQS. Figure 5c presents the median and inter-quartile ranges of predicted values from both mechanisms compared to observed concentrations binned at $10 \mathrm{ppbv}$ intervals. CB05TU overpredicts $\mathrm{O}_{3}$ when observed concentrations are lower than $60 \mathrm{ppbv}$. RACM2 increases the $\mathrm{O}_{3}$ bias over this lower concentration range. Both mechanisms perform relatively well at observed concentrations from 50 to $70 \mathrm{ppbv}$. Over $70 \mathrm{ppbv}$, CB05TU underpredicts while RACM2 improves the comparison. Thus, RACM2 better reproduces observed data at higher concentrations but overpredicts at lower concentrations.

\subsubsection{Impact on diurnal and day-to-day variation of surface $\mathrm{O}_{3}$}

Hourly diurnal observed $\mathrm{O}_{3}$ at AQS sites and the model predictions obtained with the two mechanisms are presented in Fig. 6. Predictions with both mechanisms track the diurnal pattern of observed $\mathrm{O}_{3}$. However, nighttime predicted values obtained with CB05TU are 6-8 ppbv greater than the observed values. Nighttime $\mathrm{O}_{3}$ overpredictions by atmospheric chemical transport models arise from model resolution artifacts and have been reported by other investigators (e.g., Arnold et al., 2006; and Mao et al., 2010b). CB05TU predicted peak value exceeds the observed value by $\sim 8$ ppbv. RACM2 predicted values are greater than those

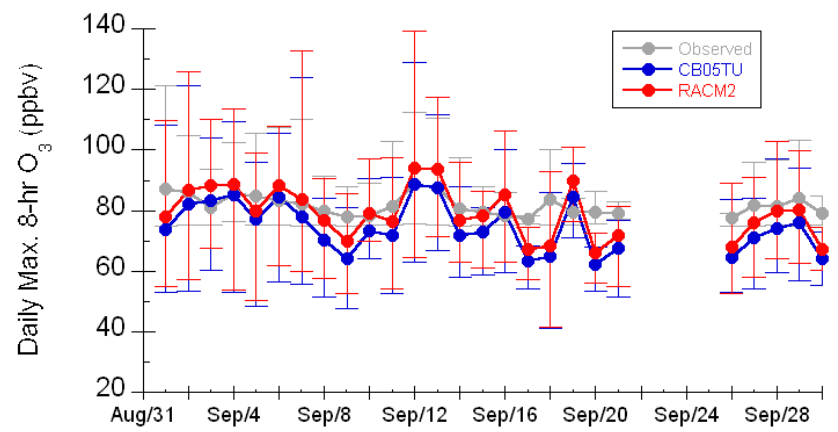

Fig. 7. A comparison of predicted daily maximum $8 \mathrm{~h} \mathrm{O} 3$ with observations from the Air Quality System (when $8 \mathrm{~h} \mathrm{O} 3>75 \mathrm{ppbv}$ ). Error bars represent minimum and maximum values.

with CB05TU and exceed the observed values by a slightly larger margin. Thus, RACM2 increases $\mathrm{O}_{3}$ predictions at all hours compared to those obtained with CB05TU.

High concentrations occur during $\mathrm{O}_{3}$ episodes. Thus, it is important that air quality models capture these high observed values. Results of average daily maximum $8 \mathrm{~h} \mathrm{O}_{3}$ predicted by the two mechanisms are compared to observations from all AQS sites in Fig. 7. We use data only when observed $8 \mathrm{~h}$ $\mathrm{O}_{3}$ values are greater than $75 \mathrm{ppbv}$. While both mechanisms tend to underpredict high observed concentrations, RACM2 captures the data better than CB05TU. The CB05TU captures the observed data better only on 7 days while RACM2 captures the observed data better on 19 days. Values do not appear in the figure on days when no observed data exceeded the threshold. Mean bias for CB05TU was $-6.6 \mathrm{ppbv}$ while mean bias for RACM2 was only $-2.2 \mathrm{ppbv}$ for the entire period. RACM2 improves mean bias by $4.4 \mathrm{ppbv}$ when observed daily maximum $8 \mathrm{~h} \mathrm{O} \mathrm{O}_{3}>75 \mathrm{ppbv}$. Thus, $\mathrm{CB} 05 \mathrm{TU}$ underpredicts $\mathrm{O}_{3}$ at the higher end of observed concentrations while RACM2 enhances and improves $\mathrm{O}_{3}$ predictions at such conditions. On the other hand, RACM2 predictions are greater than the CB05TU predictions and observed concentrations at the lower end of observed values.

\subsubsection{Impact on vertical distribution of $\mathrm{O}_{3}$}

Vertical profiles of $\mathrm{O}_{3}$ obtained with CB05TU and RACM2 at 18:00 UTC on 13 September are presented in Fig. 8. Data shown in the figure are obtained by averaging the domainwide $\mathrm{O}_{3}$ at 18:00 UTC. These vertical profiles reveal that RACM2 enhances $\mathrm{O}_{3}$ up to $11000 \mathrm{~m}$. RACM2 enhances $\mathrm{O}_{3}$ by $3-4 \mathrm{ppbv}$ from surface to $7000 \mathrm{~m}$ and $1-2 \mathrm{ppbv}$ above $7000 \mathrm{~m}$. Predictions on other days are also similar. Thus, RACM2 consistently enhances $\mathrm{O}_{3}$ from surface to upper troposphere compared to those obtained with CB05TU.

\subsection{Impact on ozone production efficiency (OPE)}

OPE has been defined by several investigators (e.g., Kleinman et al., 2002) and can be calculated from the slope 


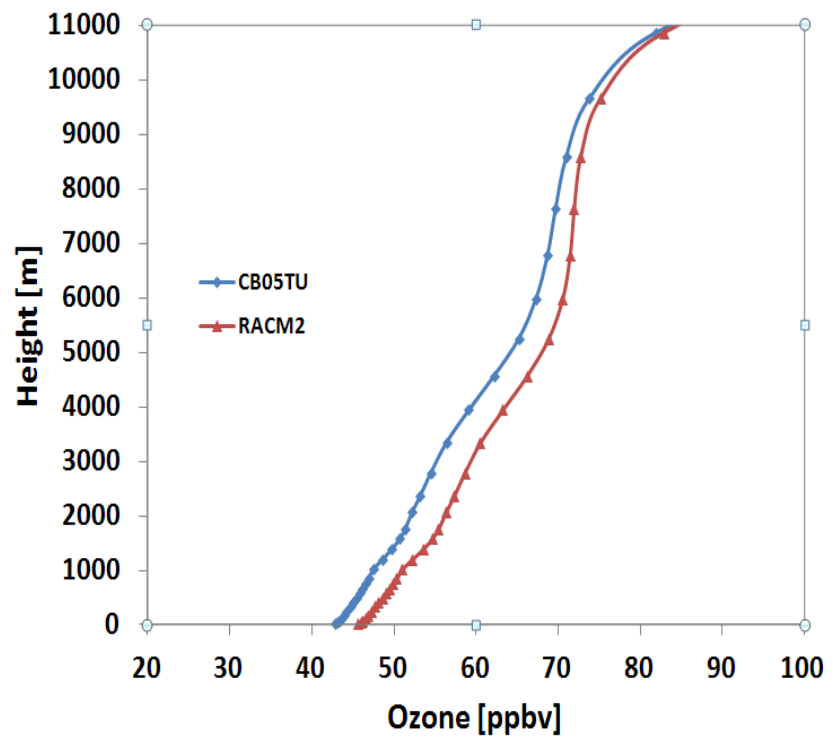

Fig. 8. Predicted vertical $\mathrm{O}_{3}$ profile obtained with $\mathrm{CB} 05 \mathrm{TU}$ and RACM2 at 18:00 UTC on 13 September.

from a linear regression of the relationship between daytime $\mathrm{O}_{3}$ and $\mathrm{NO}_{\mathrm{Z}}$ concentrations and for aged air masses $\left(\mathrm{O}_{3} / \mathrm{NO}_{\mathrm{x}}>46\right)$ (Arnold et al., 2003). OPE calculated at three different sites using model predictions and measurements from the SEARCH network are presented in Fig. 9. For the Yorkville site, OPE derived from the measurements is 8.9. The CB05TU-based value is only 5.4 while the RACM2based value is 8.4. Thus, CB05TU underpredicts OPE while the RACM2-based value agrees better with the observationbased value. A comparison of OPE derived from the Centerville and Oak Grove site measurements to model-based values also shows similar results (Fig. 9b, c). RACM2 produces more $\mathrm{O}_{3}$ while decreasing $\mathrm{NO}_{z}$; hence it enhances OPE compared to that of CB05TU.

\subsection{Impact on secondary aerosols}

\subsubsection{Impact on secondary inorganic aerosols}

Predicted monthly mean $\mathrm{SO}_{4}^{2-}$ with $\mathrm{CB} 05 \mathrm{TU}$ and the percent differences between the two mechanisms are shown in Fig. 10a and b. CB05TU predicts high $\mathrm{SO}_{4}^{2-}$ concentrations over the eastern-half of the US while predicting low concentrations in the western US. RACM2 increases $\mathrm{SO}_{4}^{2-}$ across the entire US compared to CB05TU. It increases $\mathrm{SO}_{4}^{2-}$ by $15-25 \%$ in southern California, in a portion of the southern plains, and by $5-15 \%$ in other areas. While RACM 2 enhances the production of $\mathrm{SO}_{4}^{2-}$ via the gas-phase $\mathrm{SO}_{2}$ oxidation by $\mathrm{HO}$ and the aqueous-phase $\mathrm{S}(\mathrm{IV})$ oxidation by $\mathrm{O}_{3}$, it decreases the production of $\mathrm{SO}_{4}^{2}$ via aqueous-phase $\mathrm{S}(\mathrm{IV})$ oxidation by $\mathrm{H}_{2} \mathrm{O}_{2}$, PACD, and MEPX. The increase in $\mathrm{SO}_{4}^{2-}$ production via the gas-phase $\mathrm{SO}_{2}$ oxidation by $\mathrm{HO}$ and the aqueous-phase $\mathrm{S}(\mathrm{IV})$ oxidation by $\mathrm{O}_{3}$ overwhelms the reduction in $\mathrm{SO}_{4}^{2-}$ production via aqueous-phase $\mathrm{S}(\mathrm{IV})$ oxidation by $\mathrm{H}_{2} \mathrm{O}_{2}$, PACD, and MEPX, resulting in the net increase in $\mathrm{SO}_{4}^{2-}$ predictions with RACM2. Increased $\mathrm{SO}_{4}^{2-}$ also translates to enhanced $\mathrm{NH}_{4}^{+}$. Higher $\mathrm{HNO}_{3}$ also leads to more partitioning to $\mathrm{NO}_{3}^{-}$compared to the $\mathrm{CB} 05 \mathrm{TU}$ simulation.

Ambient monitoring data from all monitoring sites in the CASTNET network are used to compare model predictions for $\mathrm{SO}_{4}^{2-}, \mathrm{NO}_{3}^{-}$, and $\mathrm{NH}_{4}^{+}$(Fig. 10c-e). While CB05TU captures $\mathrm{SO}_{4}^{2-}$ measurements at the lower observed levels, it substantially underpredicts at higher observed concentrations. However, RACM2 improves the comparisons with observed data by reducing the underpredictions at the higher observed concentrations. The slope of the fitted line of CB05TU predictions and observed data is 0.85 while the value for RACM2 is 0.95. Measured $\mathrm{NO}_{3}^{-}$from the CASTNET sites are compared to model predictions in Fig. 10d. RACM2 predictions generally are similar to or better than the CB05TU predictions. Measured $\mathrm{NH}_{4}^{+}$from the CASTNET sites are compared to model predictions in Fig. 10e. CB05TU underpredicts the observed data especially at the higher observed concentrations. RACM2 improves the comparisons with observed data by lowering the underpredictions. Similar to the comparison with observed data from CASTNET, RACM2 also improves the comparison of predicted $\mathrm{SO}_{4}^{2-}$, $\mathrm{NO}_{3}^{-}$, and $\mathrm{NH}_{4}^{+}$to observations from the Interagency Monitoring of PROtected Visual Environments (IMPROVE) network and the Speciation Trends Network (STN). The impacts of RACM2 on inorganic aerosols in the US are similar to those reported by Kim et al. (2011) for Europe. RACM2 enhances the predicted domain-wide mean $\mathrm{PM}_{2.5}$ by $7 \%$ (Table 3) compared to CB05TU. Kim et al. (2011) reported an enhancement of $6 \%$ for $\mathrm{PM}_{2.5}$ over Europe.

\subsubsection{Impact on secondary organic aerosols}

CB05TU predicted monthly mean SOA concentrations exceed $0.2 \mu \mathrm{g} \mathrm{m}^{-3}$ in most of the modeling domain (Fig. 11a). The largest concentrations are predicted in the southeastern US, northwestern US, and California. RACM2 increases SOA across the entire US compared to CB05TU. It increases SOA by $12-20 \%$ over a large portion of the eastern and western US and by $4-12 \%$ in other areas (Fig. 11b). Higher predicted oxidant levels $\left(\mathrm{HO}\right.$ and $\left.\mathrm{O}_{3}\right)$ in RACM2 result in higher production of semivolatile organic compounds from oxidation of volatile organic compounds and consequently higher SOA from both biogenic and anthropogenic precursors. It also increases the in-cloud SOA though the overall contribution of in-cloud SOA to total SOA is generally small. Impacts of RACM2 on SOA are different than those reported by Kim et al. (2011) over Europe due to the differences in the SOA chemistry between the two models. The difference in anthropogenic SOA response over Europe and the US lies primarily in differences in the SOA and gas-phase chemical 

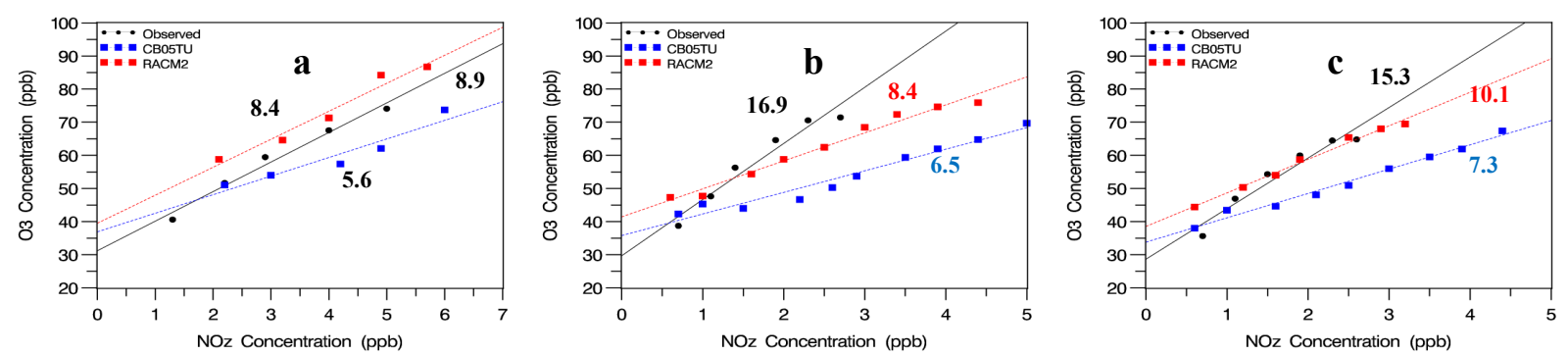

Fig. 9. A comparison of ozone production efficiency with values derived from observations from the Southeastern Aerosol Research and Characterization network sites: (a) Yorkville, Georgia; (b) Centreville, Alabama; (c) Oak Grove, Mississippi.
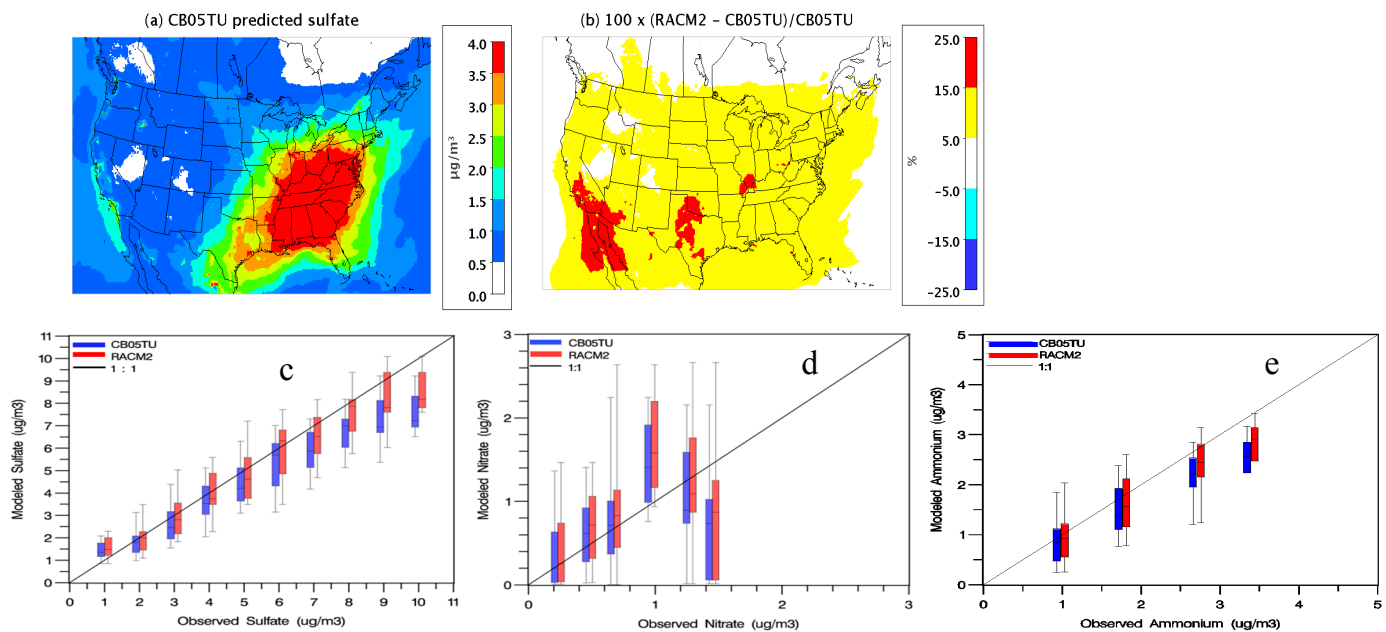

Fig. 10. (a) Predicted mean sulfate obtained with CB05TU, (b) percent differences in mean sulfate between RACM 2 and CB05TU, (c) a comparison of predicted sulfate to measurements from the CASTNET sites, (d) a comparison of predicted nitrate to measurements from the CASTNET sites, (e) a comparison of predicted ammonium to measurements from the CASTNET sites.

mechanisms used in the two studies. In our study, RACM2 leads to higher anthropogenic and biogenic SOA concentrations due to higher oxidant levels. In the European simulation, higher anthropogenic SOA is predicted with CB05, in spite of lower $\mathrm{HO}$ predictions, due to higher precursor levels. The European study specifically highlighted the higher cresol concentrations predicted with $\mathrm{CB} 05$ as a major contributor to increased anthropogenic SOA over RACM2 (Kim et al, 2011). Not only is cresol not included as an explicit precursor in CMAQ's SOA module (any SOA formed from cresol is assumed to be accounted for in the toluene SOA parameterization), but CB05TU is known to lead to significantly lower cresol concentrations than CB05. Kim et al. (2011) indicated that the discrepancy in aromatic SOA formation between CB05 and RACM2 would be significantly reduced with CB05TU, the mechanism used here. Predicted monthly mean secondary organic carbon $\left(\mathrm{OC}_{\mathrm{sec}}\right)$ obtained with the two mechanisms are compared to estimates inferred from observed data at IMPROVE sites (Fig. 11c). Mean observed $\mathrm{OC}_{\mathrm{sec}}$ concentrations are derived using the procedures described by $\mathrm{Yu}$ et al. (2004), which uses the (OC/EC) pri ra- tio, observed EC and $\mathrm{OC}$ to calculate $\mathrm{OC}_{\mathrm{sec}}$. The model with CB05TU underpredicts observed data by $0.25 \mu \mathrm{g} \mathrm{m}^{-3}$ while the model with RACM2 underpredicts observed $\mathrm{OC}_{\mathrm{sec}}$ by $0.19 \mu \mathrm{g} \mathrm{m}^{-3}$. Thus, RACM2 improves the model comparison with observed SOA.

\section{Impact on air pollution control strategy}

Air pollution control strategies are developed by performing model simulations with normal and reduced emissions and determining relative responses of the model. A relative reduction factor (RRF) is a commonly used parameter which is estimated by dividing the predicted concentrations with reduced emissions to those obtained with normal emissions (Jones et al., 2005).

\subsection{Impact on $\mathrm{O}_{3}$ control strategy}

Two additional model simulations were performed for a 10 day period in September with a $25 \% \mathrm{NO}_{\mathrm{x}}$ emission reduction with each mechanism. RRFs are estimated for 

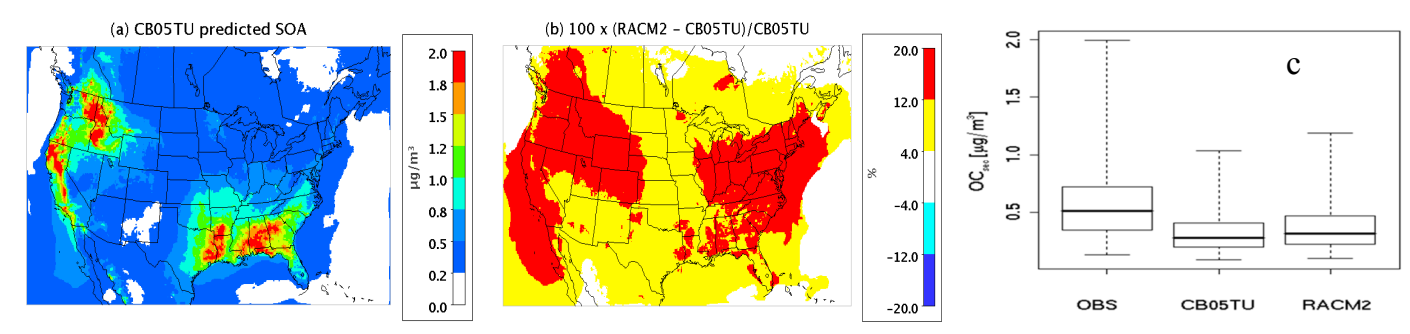

Fig. 11. (a) Predicted mean secondary organic aerosols with CB05TU (b) percent differences in mean secondary organic aerosols between RACM2 and CB05TU, (c) a comparison of predicted mean secondary organic carbon with values derived from the measurements from the Interagency Monitoring of Protected Visual Environments network.
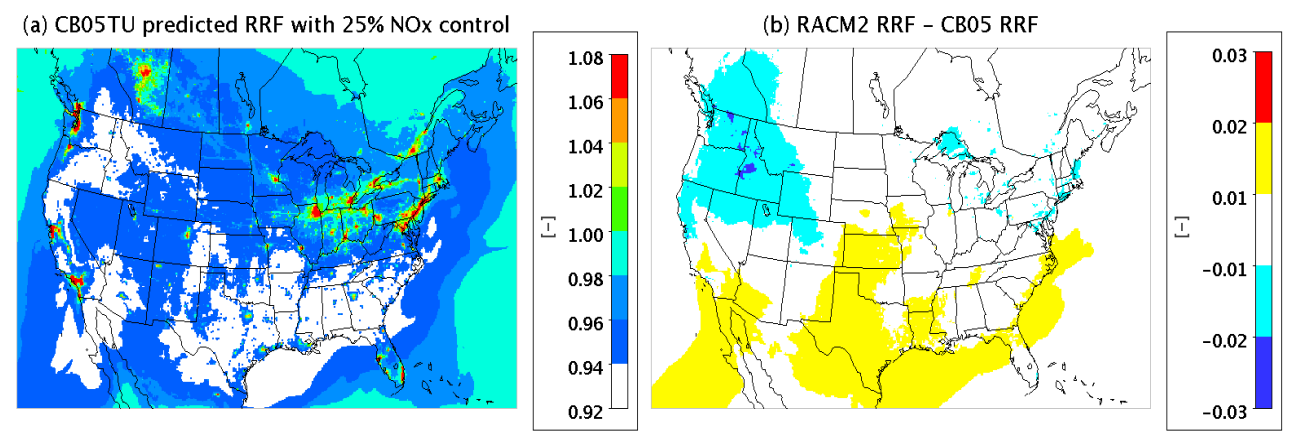

Fig. 12. (a) Relative Reduction Factors for ozone obtained with CB05TU due to $25 \% \mathrm{NO}_{\mathrm{x}}$ control, (b) differences in Relative Reduction Factors for ozone between RACM2 and CB05TU due to $25 \% \mathrm{NO}_{\mathrm{x}}$ control.

each mechanism by dividing the predicted average $\mathrm{O}_{3} \mathrm{ob}$ tained with reduced emissions to those obtained with normal emissions. Estimated RRFs with CB05TU are presented in Fig. 12a. An RRF of less than 1.0 suggests that predicted $\mathrm{O}_{3}$ decreases with reduced $\mathrm{NO}_{\mathrm{x}}$ emissions while an RRF of more than 1.0 suggests that predicted $\mathrm{O}_{3}$ increases with reduced $\mathrm{NO}_{\mathrm{x}}$ emissions. Predictions of $\mathrm{O}_{3}$ generally increase with reduced $\mathrm{NO}_{\mathrm{x}}$ emissions in urban areas. Differences in the RRFs between RACM2 and CB05TU are presented in Fig. 12b. Small negative values are found in the northwestern US and isolated areas in the Midwest while small positive values are found in the southern US. Both mechanisms exhibit similar representativeness in $\mathrm{O}_{3}$ to perturbations in $\mathrm{NO}_{\mathrm{x}}$ emissions. Thus, any control strategies developed using the two mechanisms for improving $\mathrm{O}_{3}$ are not expected to be substantially different.

\subsection{Impact on $\mathrm{PM}_{2.5}$ control strategy}

Two other model simulations were performed for the 10 day period with a $25 \% \mathrm{SO}_{2}$ emissions reduction: one with CB05TU and the other with RACM2. RRFs were estimated for each mechanism by dividing the predicted average $\mathrm{PM}_{2.5}$ obtained with reduced emissions to those obtained with normal emissions. Estimated RRFs with CB05TU are presented in Fig. 13a. RRF values are close to 1.0 for many areas, which suggests that $\mathrm{PM}_{2.5}$ does not decrease in these areas with a $25 \% \mathrm{SO}_{2}$ emissions reduction. The lowest RRF values over the land are found in the southeastern US and Mexico, which suggests this region benefits more from the $\mathrm{SO}_{2}$ reduction than other areas. The $\mathrm{SO}_{2}$ emissions reduction also shows appreciable benefit in the Midwest and surrounding areas. Differences in the RRFs between RACM2 and CB05TU are presented in Fig. 13b. Small negative values are obtained for many areas, which suggest the use of RACM2 produces marginally greater $\mathrm{PM}_{2.5}$ reduction with a $25 \% \mathrm{SO}_{2}$ emissions control. Thus, the impacts of the two mechanisms on RRFs for $\mathrm{SO}_{2}$ emissions perturbation are also small.

Similar RRFs for $\mathrm{PM}_{2.5}$ were estimated for each mechanism for simulations involving $25 \%$ reduction in $\mathrm{NO}_{\mathrm{x}}$ emissions (Fig. 13c). The lowest RRFs are found in the Midwest and surrounding areas, which suggests this region benefits more from the $\mathrm{NO}_{\mathrm{x}}$ control than other areas. $\mathrm{RRF}$ values are close to 1.0 for many areas, which suggests $\mathrm{PM}_{2.5}$ does not decrease in these areas with $25 \% \mathrm{NO}_{\mathrm{x}}$ emissions reduction. Differences in the RRFs between RACM2 and CB05TU are presented in Fig. 13d. Small negative values are found in the Midwest and other areas while positive values are found in isolated areas. Thus, the impacts of the two mechanisms on RRFs for $\mathrm{NO}_{\mathrm{x}}$ emissions control are small. Thus, both mechanisms exhibit similar RRFs for $\mathrm{PM}_{2.5}$ in response to $\mathrm{SO}_{2}$ and $\mathrm{NO}_{\mathrm{x}}$ emissions perturbations. 

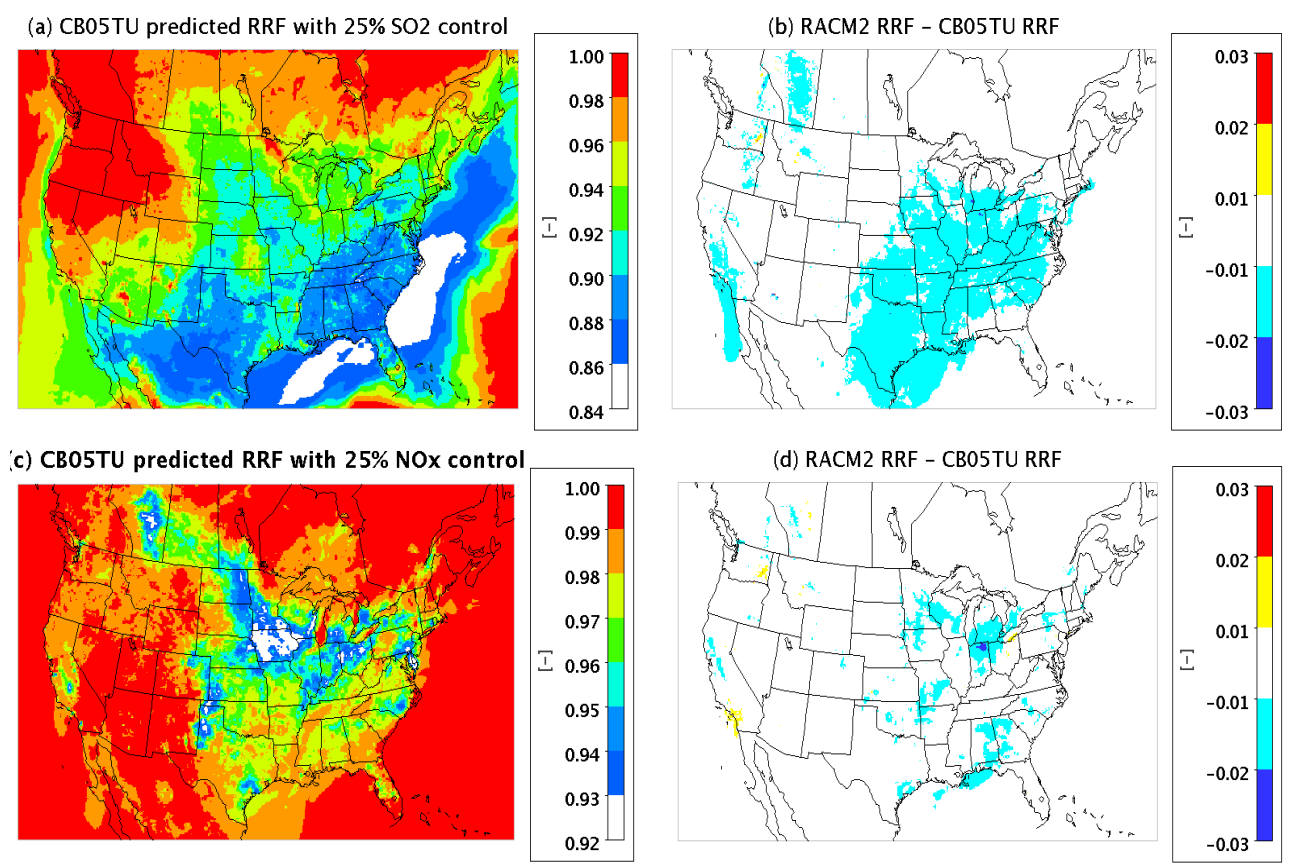

Fig. 13. (a) Relative Reduction Factors for $\mathrm{PM}_{2.5}$ obtained with $\mathrm{CB} 05 \mathrm{TU}$ due to $25 \% \mathrm{SO}_{2}$ control, (b) differences in Relative Reduction Factors for $\mathrm{PM}_{2.5}$ between RACM2 and CB05TU due to $25 \% \mathrm{SO}_{2}$ control, (c) Relative Reduction Factors for PM 2.5 obtained with CB05TU due to $25 \% \mathrm{NO}_{\mathrm{x}}$ control, (d) differences in Relative Reduction Factors for $\mathrm{PM}_{2.5}$ between RACM2 and CB05TU due to $25 \% \mathrm{NO}_{\mathrm{x}}$ control.

\section{Summary and conclusions}

We have implemented RACM2 into the CMAQ modeling system and performed month long simulations to benchmark its impacts on model predictions relative to the CB05TU mechanism as well as observed data. Model predictions of many chemical species obtained with the two mechanisms differ by relatively large margins. Predicted $\mathrm{HO}, \mathrm{TNO}_{3}$, and OPE obtained with RACM2 are greater than those obtained with CB05TU while predicted $\mathrm{H}_{2} \mathrm{O}_{2}$, MEPX, PACD, PAN, NTR, and $\mathrm{NO}_{z}$ concentrations obtained with RACM2 are lower than those obtained with CB05TU. A comparison of model predictions with the available observed data suggests that predictions obtained with RACM2 for many species agrees better with the observed data. However, it deteriorates the model performance for $\mathrm{O}_{3}$ at lower observed values. At low observed $\mathrm{O}_{3}$ levels, $\mathrm{CB} 05 \mathrm{TU}$ tends to overpredict $\mathrm{O}_{3}$ and RACM2 further overpredicts in such conditions. CB05TU underpredicts $\mathrm{O}_{3}$ at the higher end of observed values while RACM2 improves the predictions for such conditions. OPE inferred from RACM2 agree better with the observed data than those from CB05TU. Predicted secondary inorganic and organic aerosols obtained with RACM2 are greater compared to those obtained with CB05TU, which leads to improved agreements with the observed data. RACM2 and CB05TU predict similar $\mathrm{O}_{3}$ and $\mathrm{PM}_{2.5}$ concentrations, thus any air pollution control strategies are not expected to be noticeably different either.
Acknowledgements. The authors would like to thank Ryan Cleary of Computer Sciences Corporation for preparing model-ready emissions and Enhwa (Nancy) Hwang for performing CMAQ model simulations used in this study.

Edited by: R. Harley

Disclaimer. Although this paper has been reviewed by the EPA and approved for publication, it does not necessarily reflect the EPA's policies or views. W. R. Stockwell thanks the National Oceanic and Atmospheric Administration for support through Howard University's NOAA Center for Atmospheric Sciences and the National Aeronautics and Space Administration support through the Howard University Beltsville Center for Climate System Observation.

\section{References}

Appel, K. W., Gilliland, A. B., Sarwar, G., and Gilliam, R. C.: Evaluation of the Community Multiscale Air Quality (CMAQ) model version 4.5: Sensitivities impacting model performance, Part IOzone, Atmos. Environ., 41, 9603-9615, 2007.

Appel, K. W., Pouliot, G., Simon, H., Sarwar, G., Pye, H. O. T., Napelenok, S., Akhtar, F., Roselle, S.J.: Evaluation of dust and trace metal estimates from the Community Multiscale Air Quality (CMAQ) model version 5.0, Geosci. Model Dev. Discuss., 6, 1859-1899, doi:10.5194/gmdd-6-1859-2013, 2013.

Arnold, J. R., Dennis, R. L., and Tonnesen, G. S.: Diagnostic Evaluation of Numerical Air Quality Models with Specialized Ambient Observations: Testing the Community Multiscale Air Quality 
Modeling System (CMAQ) at Selected SOS 95 Ground Sites, Atmos. Environ., 37, 1185-1198, 2003.

Arnold, J. R. Dennis, R. L.: Testing CMAQ chemistry sensitivities in base case and emissions control runs at SEARCH and SOS99 surface sites in the southeastern US, Atmos. Environ., 40, 50275040, 2006.

Atkinson, R., Baulch, D. L., Cox, R. A., Crowley, J. N., Hampson, R. F., Hynes, R. G.,Jenkin, M. E., Kerr, J. A., Rossi, M. J., and Troe, J.: Summary of evaluated kinetic and photochemical data for atmospheric chemistry - IUPAC subcommittee on gas kinetic data evaluation for atmospheric chemistry, available at: http://www.iupac-kinetic.ch.cam.ac.uk/index.html, last access: 8 December 2005.

Bey, I., Jacob, D. J., Yantosca, R. M., Logan, J. A., Field, B. D., Fiore, A. M., Li, Q., Liu, H. Y., Mickley, L. J., and Schultz, M. G.: Global modeling of tropospheric chemistry with assimilated meteorology: Model description and evaluation, J. Geophys. Res., 106, 23073-23096, 2001.

Binkowski, F. S. and Roselle, S. J.: Community Multiscale Air Quality (CMAQ) model aerosol component, I: Model description, J. Geophys. Res., 108, 4183, doi:10.1029/2001JD001409, 2003.

Byun, D. and Schere, K. L.: Review of the governing equations, computational algorithms, and other components of the Models3 Community Multiscale Air Quality (CMAQ) modeling system, Appl. Mech. Rev., 59, 51-77, 2006.

Cai, C., Kelly, J. T., Avise, J. C., Kaduwela, A. P., and Stockwell, W. R.: Photochemical modeling in California with two chemical mechanisms: model intercomparison and response to emissions reductions, J. Air Waste Manage. Assoc., 61, 559-572, 2011.

Carlton, A. G., Turpin, B. J., Altieri, K. E., Seitzinger, S. P., Mathur, R., Roselle, S. J., and Weber, R. J: CMAQ model performance enhanced when in-cloud SOA is included: Comparisons of OC predictions with measurements, Environ. Sci. Technol., 42, 8798-8802, 2008.

Carlton, A. G., Bhave, P. V., Napelenok, S. L., Edney, E. O., Sarwar, G., Pinder, R. W., Pouliot, G. A., and Houyoux, M.: Model representation of secondary organic aerosol in CMAQv4.7, Environ. Sci. Technol., 44, 8553-8560, 2010.

Carter, W. P. L.: A detailed mechanism for the gas-phase atmospheric reactions of organic compounds, Atmos. Environ., 24, 481-518, 1990.

Carter, W. P. L.: Documentation of the SAPRC-99 Chemical Mechanism for VOC Reactivity Assessment, Report to the California Air Resources Board, available at: http://www.engr.ucr.edu/ carter/reactdat.htm (last access: 8 March 2013), 2000.

Carter, W. P. L.: Development of the SAPRC-07 chemical mechanism, Atmos. Environ., 44, 5324-5335, 2010.

Davis, J. M., Bhave, P. V., and Foley, K. M.: Parameterization of $\mathrm{N} 2 \mathrm{O} 5$ reaction probabilities on the surface of particles containing ammonium, sulfate, and nitrate, Atmos. Chem. Phys., 8, 52955311, doi:10.5194/acp-8-5295-2008, 2008.

Eder, B. and Yu, S.: A performance evaluation of the 2004 release of Models-3 CMAQ, Atmos. Environ., 40, 4811-4824, 2006.

Faraji, M., Kimura, Y., McDonald-Buller, E., and Allen, D.: Comparison of the Carbon Bond and SAPRC photochemical mechanisms under conditions relevant to southeast Texas, Atmos. Environ., 42, 5821-5836, 2008.
Foley, K. M., Roselle, S. J., Appel, K. W., Bhave, P. V., Pleim, J. E., Otte, T. L., Mathur, R., Sarwar, G., Young, J. O., Gilliam, R. C., Nolte, C. G., Kelly, J. T., Gilliland, A. B., and Bash, J. O.: Incremental testing of the Community Multiscale Air Quality (CMAQ) modeling system version 4.7, Geosci. Model Dev., 3, 205-226, doi:10.5194/gmd-3-205-2010, 2010.

Fountoukis, C. and Nenes, A.: ISORROPIA II: a computationally efficient thermodynamic equilibrium model for $\mathrm{K}^{+}-\mathrm{Ca}^{2+}$ $\mathrm{Mg}^{2+}-\mathrm{NH}_{4}^{+}-\mathrm{SO}_{4}^{2-}-\mathrm{NO}_{3}^{-}-\mathrm{Cl}-\mathrm{H}_{2} \mathrm{O}$ aerosols, Atmos. Chem. Phys., 7, 4639-4659, doi:10.5194/acp-7-4639-2007, 2007.

Gery, M. W., Whitten, G. Z., Killus, J. P., and Dodge, M. C.: A photochemical kinetics mechanism for urban and regional scale computer modeling, J. Geophys. Res., 94, 12925-12956, 1989.

Goliff, W. S., Stockwell, W. R., and Lawson, C. V.: The Regional Atmospheric Chemistry Mechanism, Version 2, Atmos. Environ., 68, 174-185, 2013.

Gilliam, R. C. and Pleim, J. E.: Performance assessment of new land-surface and planetary boundary layer physics in the WRFARW, J. Appl. Meteorol. Climatol., 49, 760-774, 2010.

Gilliam, R. C., Godowitch, J. M., and Rao, S. T.: Improving the horizontal transport in the lower troposphere with four dimensional data assimilation, Atmos. Environ., 53., 186-201, 2012.

Hofzumahaus, A., Rohrer, F., Lu, K., Bohn, B., Brauers, T., Chang, C.-C., Fuchs, H., Holland, F., Kita, K., Kondo, Y., Li, X., Lou, S., Shao, M., Zeng, L., Wahner, A., and Zhang, Y.: Amplified Trace Gas Removal in the Troposphere, Science, 324, 17021704, doi:10.1126/science.1164566, 2009.

Houyoux, M. R., Vukovich, J. M., Coats Jr., C. J., Wheeler, N. M., and Kasibhatla, P. S.: Emission inventory development and processing for the seasonal model for regional air quality (SMRAQ) project, J. Geophys. Res., 105, 9079-9090, 2000.

Hutzell, W. T., Luecken, D. J., Appel K. W., and Carter, W. P. L.: Interpreting predictions from the SAPRC07 mechanism based on regional and continental simulations, Atmos. Environ., 46, 417429, 2012.

IUPAC: IUPAC subcommittee for gas kinetic data evaluation, http: //www.iupac-kinetic.ch.cam.ac.uk/ (last access: 8 March 2013), 2010.

Jones, J. M., Hogrefe, C., Henry, R. F., Ku, J. Y., and Sistla, G.: an assessment of the sensitivity and reliability of the relative reduction factor approach in the development of 8-hr ozone attainment plans, J. Air Waste Manage. Assoc., 55, 13-19, 2005.

Kim, Y., Sartelet, K., and Seigneur, C.: Comparison of two gasphase chemical kinetic mechanisms of ozone formation over $\mathrm{Eu}-$ rope, J. Atmos. Chem., 62, 89-119, 2009.

Kim, Y., Sartelet, K., and Seigneur, C.: Formation of secondary aerosols over Europe: comparison of two gas-phase chemical mechanisms, Atmos. Chem. Phys., 11, 583-598, doi:10.5194/acp-11-583-2011, 2011.

Kleinman, L. I., Daum, P. H. Lee, Y.-N., Nunnermacker, L. J., Springston, S. R., Weinstein-Lloyd, J., and Rudolph, J.: ozone production efficiency in an urban area, J. Geophys. Res., 107, 4733, doi:10.1029/2002JD002529, 2002.

Lu, K. D., Hofzumahaus, A., Holland, F., Bohn, B., Brauers, T., Fuchs, H., Hu, M., Häseler, R., Kita, K., Kondo, Y., Li, X., Lou, S. R., Oebel, A., Shao, M., Zeng, L. M., Wahner, A., Zhu, T., Zhang, Y. H. and Rohrer, F.: Missing $\mathrm{OH}$ source in a suburban environment near Beijing: observed and modelled $\mathrm{OH}$ and $\mathrm{HO}_{2}$ 
concentrations in summer 2006, Atmos. Chem. Phys., 13, 10571080, doi:10.5194/acp-13-1057-2013, 2013.

Luecken, D. J., Phillips, S., Sarwar, G., and Jang, C.: Effects of using the CB05 vs. SAPRC99 vs. CB4 chemical mechanism on model predictions: Ozone and gas-phase photochemical precursor concentrations. Atmos. Environ., 42, 5805-5820, 2008.

Mao, J., Ren, X., Chen., S., Brune, W. H., Chen, Z., Martinez, M., Harder, H., Lefer, B., Rappenglück, B., Flynn, J., and Leuchner, M.: Atmospheric oxidation capacity in the summer of Houston 2006: comparison with summer measurements in other metropolitan studies, Atmos. Environ., 44, 4107-4115, 2010a.

Mao, H., Chen, M., Hegarty, J. D., Talbot, R. W., Koermer, J. P., Thompson, A. M., and Avery, M. A.: A comprehensive evaluation of seasonal simulations of ozone in the northeastern US during summers of 2001-2005, Atmos. Chem. Phys., 10, 9-27, doi:10.5194/acp-10-9-2010, 2010 b.

Mollner, A. K., Valluvadasan, S., Feng, L., Sprague, M. K., Okumura, M., Milligan, D. B., Bloss, W. J., Sander, S. P., Martien, P. T., Harley, R. A., McCoy, A. B., and Carter, W. P. L.: Rate of gas phase association of hydroxyl radical and nitrogen dioxide, Science, 330, 646-649, 2010.

Parrish, D. D., Allen, D. T., Bates, T. S., Estes, M., Fehsenfeld, F.C., Feingold, G., Ferrare, R., Hardesty, R. M., Meagher, J. F., Nielsen-Gammon, J. W., Pierce, R. B., Ryerson, T. B., Seinfeld, J. H., and Williams, E. J.: Overview of the second Texas Air Quality Study (TexAQS II) and the Gulf of Mexico Atmospheric Composition and Climate Study (GoMACCS), J. Geophys. Res., 114, D00F13, doi:10.1029/2009JD011842, 2009.

Pouliot, G., Pierce, T., Gon, H. D. V. D., Schaap, M., Moran, M., and Nopmongcol, U.: Comparing emission inventories and model-ready emission datasets between Europe and North America for the AQMEII project, Atmos. Environ., 53, 4-14, 2012.

Sander, S. P., Friedl, R. R., Ravishankara, A. R., Golden, D. M., Kolb, C. E., Kurylo, M. J., Huie, R. E., Orkin, V. L., Molina, M. J., Morrtgat, G. K., Finlayson-Pitts, B. J.: Chemical kinetics and photochemical data for use in atmospheric studies, evaluation number 14, NASA Jet Propulsion Laboratory, available at: http://jpldataeval.jpl.nasa.gov/download.html (last access: 8 March 2013), 2003.

Sander, S. P., Abbatt, J. P. D., Barker, J. R., Burkholder, J. B., Friedl, R. R., Golden, D. M., Huie, R. E., Kolb, C. E., Kurylo, M. J., Moortgat, G. K., Orkin, V. L., and Wine, P. H.: Chemical Kinetics and Photochemical Data for Use in Atmospheric Studies, Evaluation No. 17, Jet Propulsion Laboratory, Pasadena, CA, 2011.

Sandu, A., Verwer, J. G. Blom, E. J. Spee, G. R. Carmichael, and F. A. Potra, 1997. Benchmarking stiff ODE solvers for atmospheric chemistry problems II: Rosenbrock solvers, Atmos. Environ., 31, 3459-3472.

Sarwar, G., Luecken, D., Yarwood, G., Whitten, G., and Carter, B.: Impact of an updated Carbon Bond mechanism on air quality using the Community Multiscale Air Quality modeling system: preliminary assessment, J. Appl. Meteorol. Clim., 47, 3-14, 2008.

Sarwar, G., Appel, K. W., Carlton, A. G., Mathur, R., Schere, K., Zhang, R., and Majeed, M. A.: Impact of a new condensed toluene mechanism on air quality model predictions in the US, Geosci. Model Dev., 4, 183-193, doi:10.5194/gmd-4-183-2011, 2011.
Sarwar, G., Fahey, F., Kwok, R., Gilliam, R., Xue, J., Jianzhen, Y., and Carter, W. P. L.: Examining the potential impacts of the aqueous-phase $\mathrm{S}(\mathrm{IV})$ oxidation by $\mathrm{NO}_{2}$ and the gas-phase $\mathrm{SO}_{2}$ oxidation by the Stabilized Criegee Intermediate on sulfate, Atmos. Environ., 68, 186-197, 2013.

Schwede, D., Pouliot, G., and Pierce, T.: Changes to the biogenic emissions inventory system version 3 (BEIS3), in: 4th Annual CMAS Models-3 Users' Conference, 26-28 September 2005, UNC-Chapel Hill, NC, 1-6, available at: http://www. cmascenter.org/conference/2005/abstracts/2_7.pdf (last access: 8 March 2013), 2005.

Seigneur, C. and Saxena, P.: A theoretical investigation of sulfate formation in clouds, Atmos. Environ. 22, 101-115, 1988.

Shearer, M. S., Harley, R. A., Jin, L., and Brown, N. J.: Comparison of SAPRC99 and SAPRC07 mechanisms in photochemical modeling for central California, Atmos. Environ., 46, 205-216, 2012.

Skamarock, W. C., Klemp, J. B., Dudhia, J., Grill, D. O., Barker, D. M., Duda, M. G, Huang, X-Y, Wang, W., and Powers, J. G.: A description of the advanced research WRF version 3. NCAR Tech Note NCAR/TN 475 STR, 125 pp. available from UCAR Communications, P.O. Box 3000, Boulder, CO 80307, 2008.

Stockwell, W. R.: A Homogeneous Gas Phase Mechanism for use in a Regional Acid Deposition Model, Atmos. Environ., 20, 16151632, 1986.

Stockwell, W. R., Middleton, P., Chang, J. S., and Tang, X.: The second generation Regional Acid Deposition Model chemical mechanism for regional air quality modeling, J. Geophys. Res., 95, 16343-16367, 1990.

Stockwell, W. R., Kirchner, F., Kuhn, M., and Seefeld, S.: A new mechanism for regional atmospheric chemistry modeling, J. Geophys. Res. 102, 25847-25879, 1997.

Trainer, M., Parish, D. D., Goldan, P. D., Roberts, J., and Fehsenfeld, F. C.: Review of observation-based analysis of the regional factors influencing ozone concentrations. Atmos. Environ., 2045-2061, 2000.

Yarwood, G., Rao, S., Yocke, M., and Whitten, G.: Updates to the Carbon Bond Chemical Mechanism: CB05, Final Report to the US EPA, RT-0400675, available at: http://www.camx.com (last access: 8 March 2013), 2005.

Yu, S., Dennis, R. L., Bhave, P. V., and Eder, B. K.: Primary and secondary organic aerosols over the United States: estimates on the basis of observed organic carbon (OC) and elemental carbon (EC), and air quality modeled primary OC/EC ratios, Atmos. Environ., 38, 5257-5268, 2004.

Yu, S., Mathur, R., Sarwar, G., Kang, D., Tong, D., Pouliot, G., and Pleim, J.: Eta-CMAQ air quality forecasts for $\mathrm{O}_{3}$ and related species using three different photochemical mechanisms (CB4, CB05, SAPRC-99): comparisons with measurements during the 2004 ICARTT study, Atmos. Chem. Phys., 10, 30013025, doi:10.5194/acp-10-3001-2010, 2010.

Yu, S., Mathur, R., Pleim, J., Pouliot G., Wand, D., Eder, B., Schere, K., Gilliam, R., and Rao, S. T.,: Comparative evaluation of the impact of WRF-NMM and WRF-ARW meteorology on CMAQ simulations for $\mathrm{O}_{3}$ and related species during the 2006 TexAQS/GoMACCS campaign, Atmos. Pollut. Res., 3, 149-162, 2012.

Whalley, L. K., Edwards, P. M., Furneaux, K. L., Goddard, A., Ingham, T., Evans, M. J., Stone, D., Hopkins, J. R., Jones, C. E., 
Karunaharan, A., Lee, J. D., Lewis, A. C., Monks, P. S., Moller, S. J., and Heard, D. E.: Quantifying the magnitude of a missing hydroxyl radical source in a tropical rainforest, Atmos. Chem. Phys., 11, 7223-7233, doi:10.5194/acp-11-7223-2011, 2011.

Whitten, G. Z., Heo., G., Kimura, Y., McDonald-Buller, E., Allen, D., Carter, W. P. L., and Yarwood, G.: A new condensed toluene mechanism for Carbon Bond: CB05-TU, Atmos. Environ., 44, 5346-5355, 2010.
Zhang, X., Chen, Z. M., He, S. Z., Hua, W., Zhao, Y., and Li, J. L.: Peroxyacetic acid in urban and rural atmosphere: concentration, feedback on $\mathrm{PAN}-\mathrm{NO}_{\mathrm{x}}$ cycle and implication on radical chemistry, Atmos. Chem. Phys., 10, 737-748, doi:10.5194/acp10-737-2010, 2010. 